\title{
Organic Synthesis with Bimetallic Systems
}

\author{
Shin Kamijo and Yoshinori Yamamoto
}

1.1

Introduction

The application of bimetallic systems to organic synthesis has emerged dramatically in recent years, and great progress has been made in research aimed at developing reactions promoted with catalytic amounts of activating reagents. The cross-coupling reaction is a representative example of this type of transformation. In the early stages of the investigations, most studies were focused on transition metal (TM)catalyzed reactions using main group organometallic compounds $\left(\mathrm{R}^{2}-\mathrm{M}\right)$. The organometallic compound $\left(\mathrm{R}^{2}-\mathrm{M}\right)$ was used as a coupling partner of the substrate $\left(\mathrm{R}^{1}-\mathrm{X}\right)$; the cross-coupling reactions can be regarded as transformations promoted by a bimetallic system (cat. TM/stoichiometric $\mathrm{R}^{2}-\mathrm{M}$ ) (Figure 1.1a). Not only crosscoupling reactions (Section 1.2.1), but also reactions of $\pi$-allylpalladium complexes (Section 1.2.4) and nickel-catalyzed three-component coupling (TCC) reactions (Section 1.2.5) can be classified as belonging to category a. The conjugate addition of organomagnesium and -lithium reagents to Michael acceptors in the presence of catalytic amounts of copper salts also belongs to this category, but such organocopper reactions are not mentioned in this chapter since many excellent reviews and monographs have been published on these topics in recent years [1]. Another characteristic feature of these cross-coupling reactions is that an enhancement of the reaction rate is often observed in the presence of an additional metal salt (MX). The coupling reaction between $R^{1}-X$ and $R^{2}-M$ proceeds very smoothly in the presence of catalytic amounts of TM and stoichiometric amounts of MX (Figure 1.1b). Wacker reactions (Section 1.2.2), Heck reactions (Section 1.2.3), most of the reactions involving $\pi$-allylpalladium complexes (Section 1.2.4), and NozakiHiyama-Kishi (NHK) reactions (Section 1.2.6) belong to this category b. We will discuss the reactions promoted by a combination of catalytic and stoichiometric amounts of metals (categories a and $\mathbf{b}$ ) in the first section.

Recent studies have revealed that a wide variety of bimetallic catalytic systems composed of a transition metal and an additional metal salt (cat. TM/cat. MX) efficiently catalyze organic transformations, such as the cross-coupling reaction

Multimetallic Catalysts in Organic Synthesis. Edited by M. Shibasaki and Y. Yamamoto Copyright (C) 2004 WILEY-VCH Verlag GmbH \& Co. KGaA, Weinheim

ISBN: $3-527-30828-8$ 
2| 1 Organic Synthesis with Bimetallic Systems

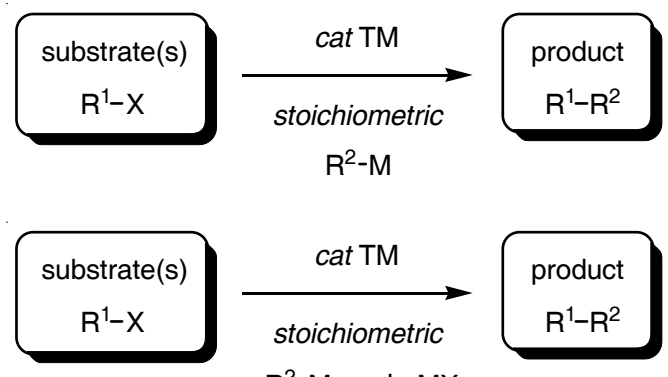

Figure 1.1

$$
\mathrm{R}^{2}-\mathrm{M} \text { and } \mathrm{MX}
$$

between $\mathrm{R}^{1}-\mathrm{X}$ and $\mathrm{R}^{2}-\mathrm{M}$ (Figure $1.2 \mathrm{c}$ ), the Wacker reaction, reactions involving $\pi$-allylpalladium complexes, and so forth (category $\mathrm{c}$ ). The MX catalyst often promotes these reactions by forming a reactive species in situ via transmetalation and halide abstraction. In some cases, the MX catalyst behaves as a Lewis acid and activates the substrates and intermediates through coordination. The reactions belonging to category $\mathrm{c}$ are mentioned in Sections 1.3.1 to 1.3.5. The utilization of dinuclear metal catalysts (cat. M-M) is one of the approaches to realize new catalytic transformations, although application of such catalytic systems to organic synthesis is not so popular and relatively few examples have been reported to date. The reactions belonging to this category $\mathbf{d}$ are mentioned in Sections 1.3.6.1 and 1.3.6.2 (Figure 1.2d). The unique catalytic properties of $\mathrm{M}-\mathrm{M}$ catalysts originate from double activation by the two metal centers. Several combinations of two transition metals (cat. $\mathrm{TM}^{1} /$ cat. $\mathrm{TM}^{2}$ ) have been applied in both one-pot and sequential reactions (Figure 1.2e). The overall transformation is achieved through the two successive reactions promoted by each transition metal catalyst. The Pauson-Khand (Section 1.3.4.4) and sequential reactions (Section 1.3.6.3) are classified as belonging to this category e. We will discuss the reactions promoted by a combination of catalytic amounts of two metals (categories $\mathbf{c}, \mathbf{d}, \mathbf{e}$ ) in the second part of this chapter. The details of each reaction will be considered in each section.
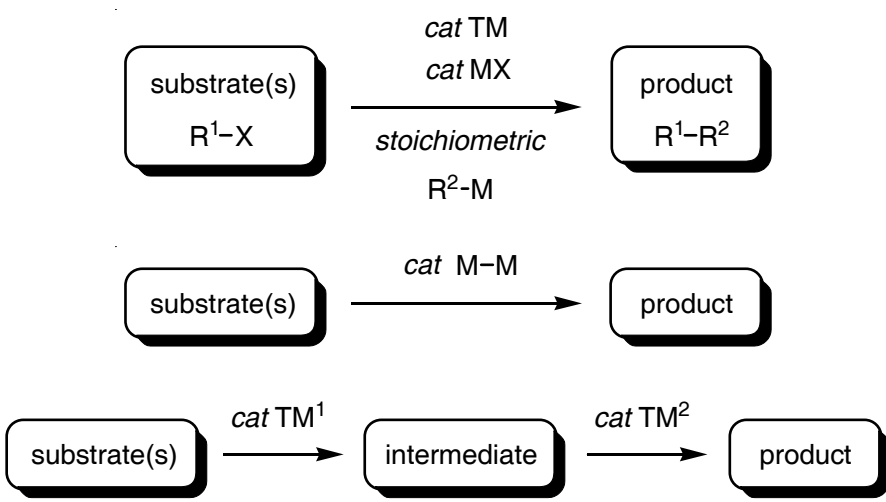

Figure 1.2 
1.2

Reactions Promoted by a Combination of Catalytic and Stoichiometric Amounts of Metals

1.2.1

Transition Metal-Catalyzed Cross-Coupling Reactions

Transition metal-catalyzed cross-coupling reactions have been developed by employing various combinations of catalysts and organometallic compounds [2]. Although the organometallic compounds are exploited as a reagent, the crosscoupling reactions can be regarded as transformations promoted by a bimetallic system. A representative reaction scheme and catalytic cycle are depicted in Scheme 1.1. Generally, the reactions begin with oxidative addition of transition metal catalysts (TM) to aryl and alkenyl halides $R^{1}-X(1)$ to form the intermediates 4 . Transmetalation between 4 and organometallic compounds $\mathrm{R}^{2}-\mathrm{M}(2)$ affords the intermediates $\mathbf{5}$, and reductive elimination of TM catalysts results in the formation of a carbon-carbon bond to furnish the coupling products $R^{1}-R^{2}(3)$. Palladium and nickel catalysts usually show excellent activities in these transformations.

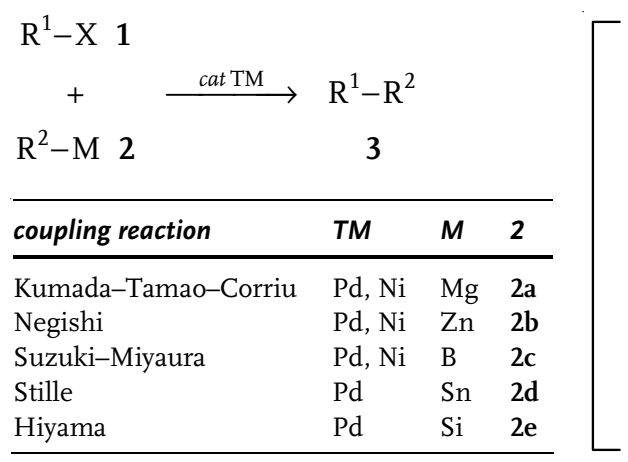

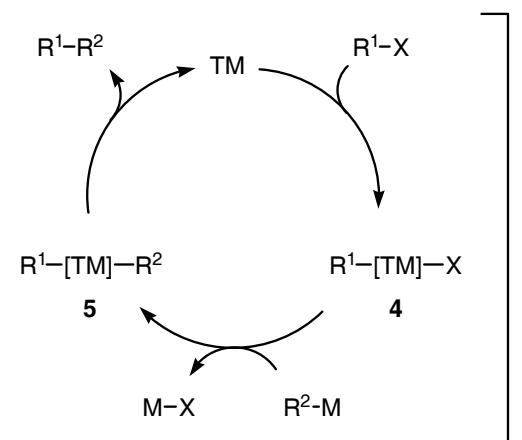

Scheme 1.1

The first successful nickel-catalyzed cross-coupling reaction between halides and Grignard reagents $\mathrm{R}^{2}-\mathrm{MgX}$ (2a) was simultaneously achieved by two research groups and is now referred to as the Kumada-Tamao-Corriu reaction. The palladium-catalyzed cross-coupling reaction between halides and organozinc reagents $\mathrm{R}^{2}-\mathrm{ZnX}(\mathbf{2 b})$ was developed by Nigishi and co-workers. Some reactions were also catalyzed by a nickel complex. Organozinc reagents are most conveniently prepared in situ from organolithium, -magnesium, or -aluminum compounds with a $\mathrm{ZnX}_{2}$ salt. The use of organozinc reagents extended the range of compatibility to functional groups such as ketones, esters, cyano, and amide groups, which react with Grignard reagents. Suzuki and Miyaura et al. investigated the palladiumcatalyzed coupling reaction of halides with organoboron compounds $\mathrm{R}^{2}-\mathrm{BR}_{2}(2 \mathrm{c})$. The addition of base is required to activate either the boron reagent or the $\mathrm{Pd}$ catalyst in order to promote the coupling reaction. This transformation is widely applied due to its high tolerance of a broad range of functionalities and of water. 
4| 1 Organic Synthesis with Bimetallic Systems

Coupling reactions between halides and organotin compounds $\mathrm{R}^{2}-\mathrm{SnR}_{3}{ }_{3}(\mathbf{2 d})$ in the presence of a palladium catalyst have been extensively studied and are now referred to as the Stille coupling reaction. This transformation proceeds under essentially neutral conditions. The standard catalyst system is a combination of a $\mathrm{Pd}$ catalyst with a ligand such as (2-furyl $)_{3} \mathrm{P}$ or $\mathrm{AsPh}_{3}$. Although the Stille coupling reaction is an excellent carbon-carbon bond-forming procedure, unsatisfactory results are sometimes encountered due to substrate instability. Therefore, many additives have been examined for an accelerating effect on the reaction. Gronowitz and co-workers [3] employed $\mathrm{Ag}_{2} \mathrm{O}$ as an activator in the reaction between 2-iodopyridine and a stannylthiophene (Scheme 1.2). Migita and co-workers [4] observed an acceleration of the coupling reaction between aryl bromides and $\alpha$-stannylacetate by utilizing $\mathrm{ZnBr}_{2}$ as an additive (Scheme 1.3). Corey and co-workers [5] applied $\mathrm{CuCl}$ as an activator for coupling reactions between aryl nonaflate and vinylstannanes (Scheme 1.4).
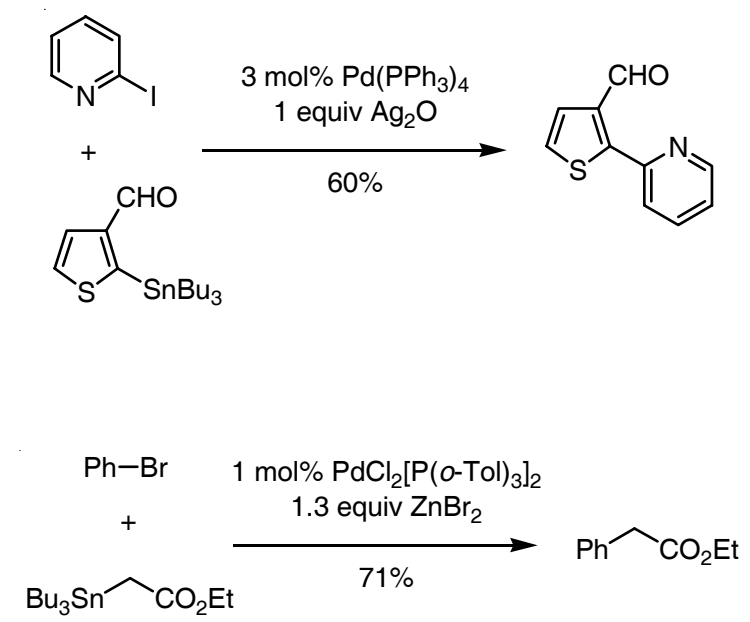

Scheme 1.4

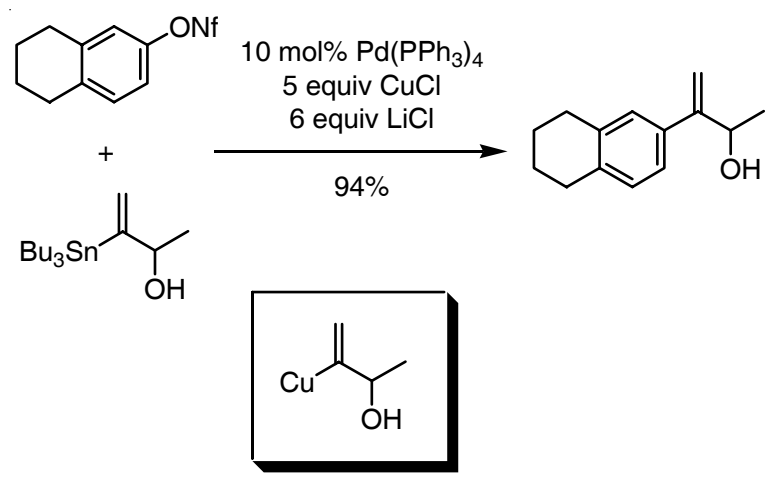


Scheme 1.5
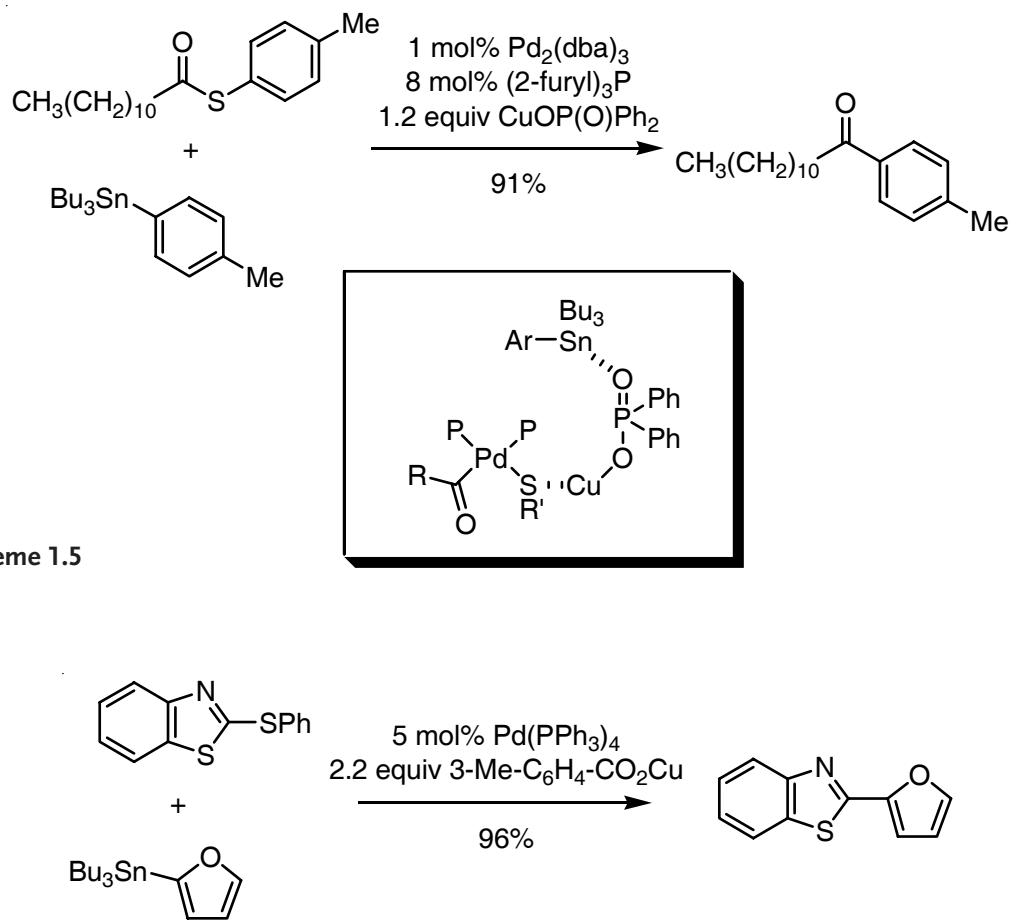

\section{Scheme 1.6}

These reaction activators most probably facilitate transmetalation of the organic group from the stannane to the palladium center through the formation of more reactive organometallic species such as vinylcopper, as shown in Scheme 1.4. Liebeskind and co-workers [6] have recently reported the Stille-type coupling reaction between thiol esters and organostannanes (Scheme 1.5) The reaction proceeded in the presence of a combination of $\mathrm{Pd}_{2}(\mathrm{dba})_{3} /(2 \text {-furyl })_{3} \mathrm{P}$ as catalyst and $\mathrm{CuOP}(\mathrm{O}) \mathrm{Ph}_{2}$ as an activator. The role of the $\mathrm{Cu}$ additive is activation of the acylpalladium thiolate intermediate to facilitate transmetalation of the aryl group from the stannane to the palladium atom. These authors applied a similar $\mathrm{Pd}-\mathrm{Cu}$ bimetallic catalyst to the coupling reaction between a heteroaromatic thioether and an organostannane (Scheme 1.6) [7]. The same type of reaction was also reported by Guillaumet and co-workers [8]. Migita and co-workers [9] developed a method for the $\alpha$-arylation of ketones based on a coupling reaction between enol acetates and bromobenzene (Scheme 1.7) The key to realizing this coupling reaction is to perform it in the presence of a combination of $\mathrm{PdCl}_{2}\left(\text { o-tolyl }{ }_{3} \mathrm{P}\right)_{2}$ catalyst and $\mathrm{Bu}_{3} \mathrm{SnOMe}$. The enol acetates are transformed in situ to the corresponding tributyltin enolates, which react with the Pd intermediate to afford the coupling product. A similar coupling reaction utilizing silyl enol ethers and aryl bromides was investigated by Kuwajima et al. (Scheme 1.8) [10]. In this case, the addition of $\mathrm{Bu}_{3} \mathrm{SnF}$ in combination with $\mathrm{PdCl}_{2}\left(\text { o-tolyl }{ }_{3} \mathrm{P}\right)_{2}$ is essential for successful reaction. 
6| 1 Organic Synthesis with Bimetallic Systems

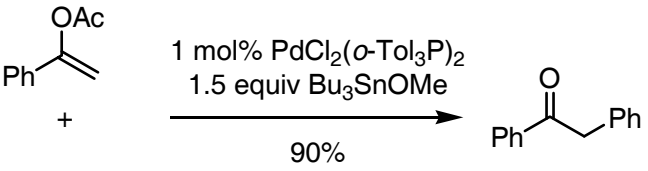

$\mathrm{Br}-\mathrm{Ph}$

Scheme 1.7
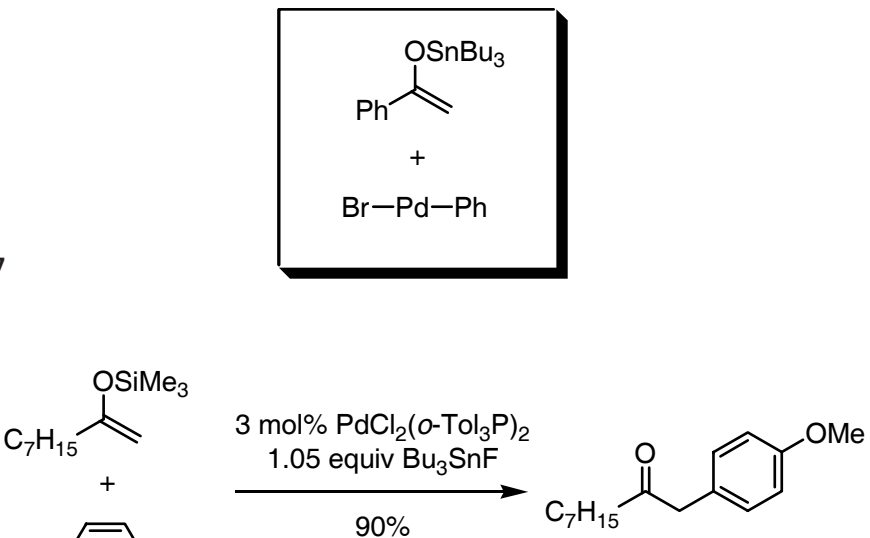

Scheme 1.8

Hiyama and co-workers found that a cross-coupling reaction between halides and organosilanes $\mathrm{R}^{2}-\mathrm{SiR}_{3}{ }_{3}(\mathrm{e})$ could be achieved in the presence of a palladium catalyst combined with a fluoride anion source such as tetrabutylammonium fluoride (TBAF) or tris(dimethylamino)sulfur (trimethylsilyl)difluoride (TASF). The addition of a fluoride source is essential to facilitate transmetalation of the organic group through the formation of a five-coordinate silicate species. Hiyama and Mori et al. [11] applied silanols as coupling partners with aryl iodides in the cross-coupling reaction (Scheme 1.9). The reaction proceeded particularly well in the presence of $\mathrm{Ag}_{2} \mathrm{O}$ as an activator with a catalytic amount of $\mathrm{Pd}\left(\mathrm{PPh}_{3}\right)_{4}$. A fluoride activator such as TBAF, which is often employed for the usual Hiyama coupling reaction using a fluorosilane as a starting material, failed to give the corresponding adduct. The role of the Ag additive can be rationalized in terms of two cooperative

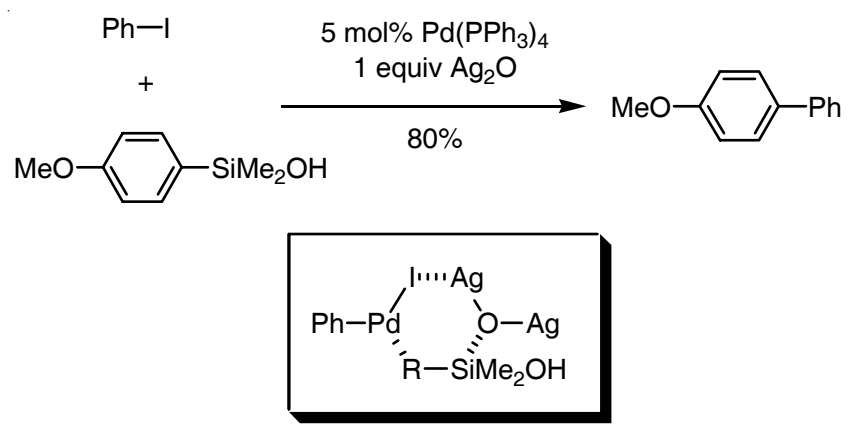

Scheme 1.9 
functions, which may be outlined as follows. One is the formation of a pentacoordinate silicate species to facilitate transmetalation of the aryl group from the $\mathrm{Si}$ to the Pd atom, and the other is interaction with the iodide on the organopalladium intermediate to make transmetalation feasible. A similar reaction using alkynylsilanols as coupling partners has been reported by Chang and co-workers [12].

\section{2 .2}

\section{The Wacker Reaction}

The synthesis of acetaldehyde $7(\mathrm{R}=\mathrm{H})$ by oxidation of ethylene $\mathbf{6}(\mathrm{R}=\mathrm{H})$ in the presence of a catalytic amount of $\mathrm{PdCl}_{2}$ and a stoichiometric amount of $\mathrm{CuCl}_{2}$ is known as the Wacker process (Scheme 1.10) [13]. The reaction involves nucleophilic addition of $\mathrm{H}_{2} \mathrm{O}$ to ethylene coordinated by $\mathrm{PdCl}_{2}$. The Pd catalyst activates the carbon-carbon double bond by $\pi$-coordination. The $\mathrm{Cu}$ additive serves to oxidize the generated $\mathrm{Pd}^{0}$ species so as to regenerate the $\mathrm{PdCl}_{2}$ catalyst. The role of oxygen is assumed to be oxidation of the $\mathrm{CuCl}$ produced to regenerate the $\mathrm{CuCl}_{2}$ additive, although a stoichiometric amount of $\mathrm{CuCl}_{2}$ is employed in most cases. The reaction has been extended to substituted alkenes.
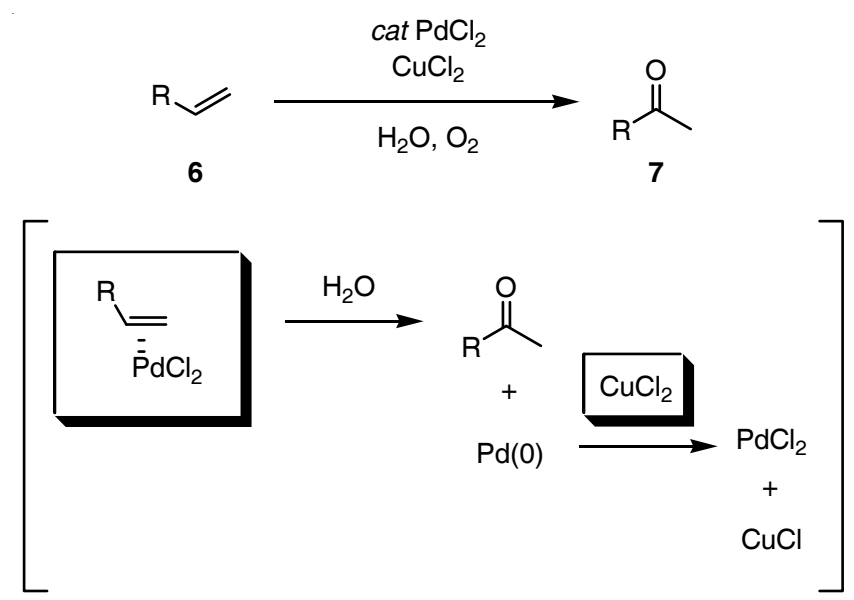

\section{Scheme 1.10}

Wacker-type reactions have been successfully applied for the formation of a wide variety of heterocyclic compounds. For example, various kinds of oxygen-containing heterocycles, such as tetrahydrofuran (Scheme 1.11) [14] and benzofuran derivatives (Scheme 1.12) [15], have been synthesized in the presence of a catalytic amount of

Scheme 1.11

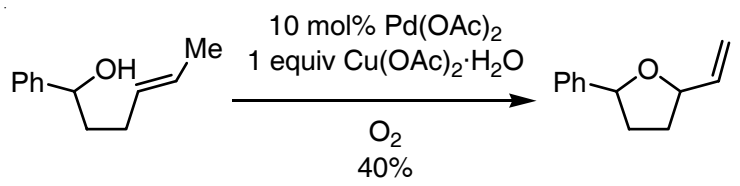




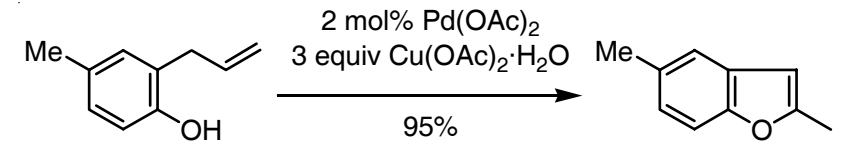

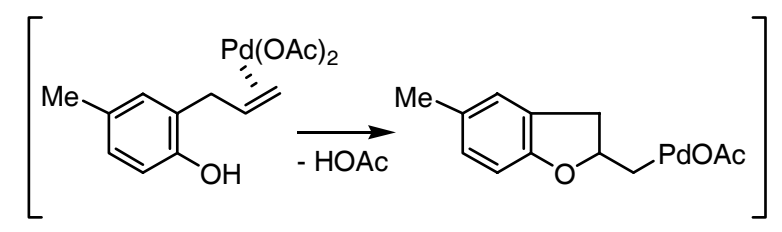

Scheme 1.12

a $\mathrm{Pd}^{\mathrm{II}}$ species and a stoichiometric amount of $\mathrm{Cu}$ oxidant. The reactions involve intramolecular alkoxypalladation of the alkene to form a $\sigma$-alkylpalladium intermediate, followed by $\beta$-elimination to furnish the cyclized products.

When the reaction was conducted under $\mathrm{CO}$ atmosphere, insertion of $\mathrm{CO}$ into the $\sigma$-alkylpalladium species took place to afford carbonylated products. Semmelhack et al. investigated the synthesis of pyran derivatives by using a combination of $\mathrm{Pd}(\mathrm{OAc})_{2}$ and $\mathrm{CuCl}_{2}$ oxidant under $\mathrm{CO}$ gas (Scheme 1.13) [16]. Tamaru and co-workers [17] succeeded in obtaining bicyclic lactone derivatives via the intramolecular alkoxycarbonylation reaction using a Pd-Cu system (Scheme 1.14). Semmelhack et al. [18] also succeeded in trapping an alkylpalladium intermediate with alkenes and the corresponding carbon chain elongated products were obtained (Scheme 1.15).

The reaction has also been applied for the synthesis of nitrogen-containing cyclic compounds. Gallagher and co-workers [19] subjected allenyl amides to a CO atmosphere in the presence of $\mathrm{PdCl}_{2}$ and $\mathrm{CuCl}_{2}$ and thereby obtained pyrrolidine

Scheme 1.13

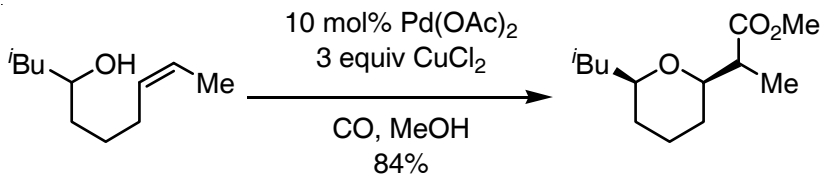

Scheme 1.14

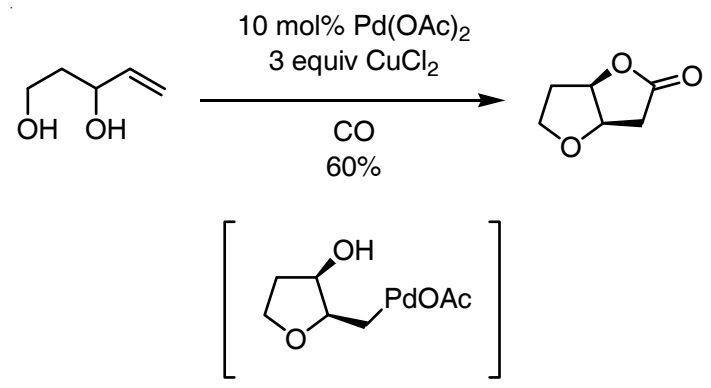


1.2 Reactions Promoted by a Combination of Catalytic and Stoichiometric Amounts of Metals $\mid 9$

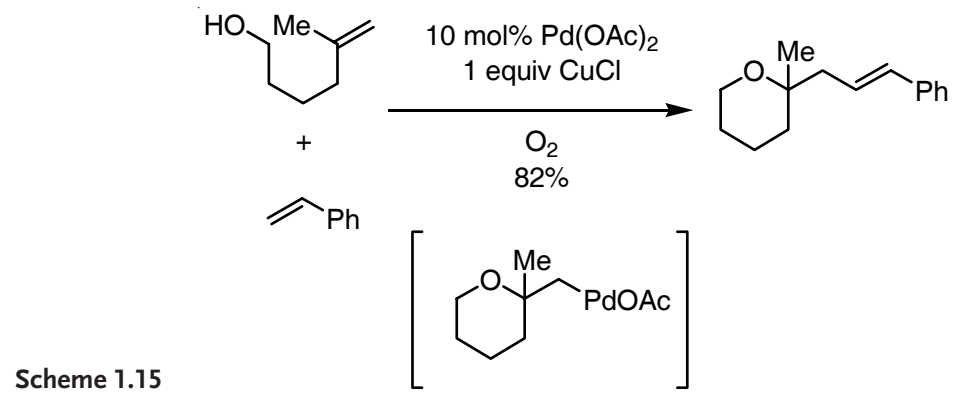

Scheme 1.16

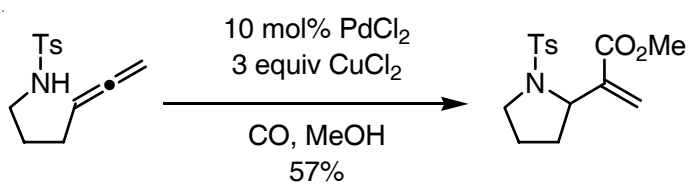

Scheme 1.17<smiles>[3H]N1C(=O)OCC1C(=C)C</smiles>

Scheme 1.18

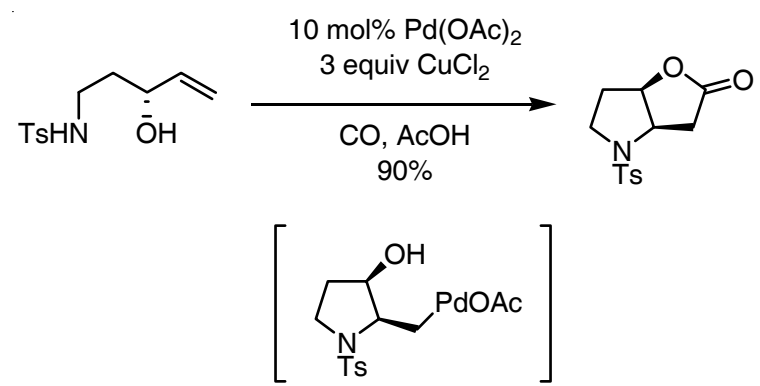

derivatives (Scheme 1.16). A similar cyclization has been reported by Tamaru and co-workers [20] (Scheme 1.17). Tamaru and co-workers [21] also observed the formation of bicyclic compounds through an intramolecular aminocarbonylation reaction using a $\mathrm{Pd}-\mathrm{Cu}$ system (Scheme 1.18).

Widenhoefer et al. [22] reported a similar type of cyclization reaction using a $\mathrm{Pd}-\mathrm{Cu}$ bimetallic system. The reaction probably proceeds through addition of the enolate to the alkene activated by coordination of the Pd complex (Scheme 1.19). 
<smiles>COC(=O)CCCC(=O)OC</smiles>

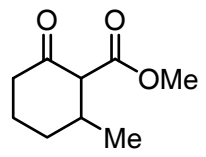

$87 \%$

The combination a catalytic amount of $\mathrm{PdCl}_{2}(\mathrm{MeCN})_{2}$ and a stoichiometric amount of $\mathrm{Yb}(\mathrm{OTf})_{3}$ was also found to be effective by Yang and co-workers [23]. The catalytic use of $\mathrm{Yb}(\mathrm{OTf})_{3}$ proved to be effective for some substrates, although the use of a stoichiometric amount of $\mathrm{Yb}(\mathrm{OTf})_{3}$ was seemingly required to obtain the desired carbocycles in good yields.

\section{2 .3}

\section{The Heck Reaction}

The $\mathrm{Pd}^{0}$-catalyzed coupling of an aryl or vinyl halide or triflate with an alkene is known as the Heck reaction [24]. The reaction is normally carried out using a Pd catalyst with phosphine ligands under basic conditions. Investigations aimed at selecting the optimal additive for the Heck reaction revealed that the addition of an Ag salt increased the reaction rate and led to consistently higher reactivities compared to the original catalyst systems.

A stoichiometric amount of silver additive was first employed in the coupling reaction between iodobenzenes and vinylsilane by Hallberg and co-workers [25] (Scheme 1.20). When this reaction was carried out in the presence of a combination of a catalytic amount of $\mathrm{Pd}(\mathrm{OAc})_{2} / \mathrm{PPh}_{3}$ and a stoichiometric amount of $\mathrm{AgNO}_{3}$, styrylsilanes were obtained without the formation of any desilylated styrenes, which are the products under the standard conditions of the Heck reaction. The addition of the Ag salt suppressed cleavage of silyl group during the course of the reaction.

Scheme 1.20

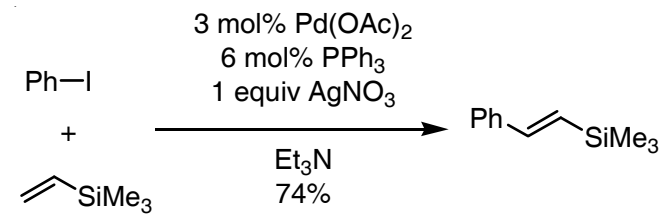

Overman and co-workers [26] found that the addition of a silver salt minimized alkene isomerization in the derived products (Scheme 1.21). Jeffery [27] reported that the addition of an Ag salt to suppress alkene isomerization was especially effective in reactions using allyl alcohols as coupling partners (Scheme 1.22). The formation of aldehydes could be avoided by simply adding a stoichiometric amount of AgOAc to the reaction mixture.

Acceleration of reaction rates and enhancement of enantioselectivity were observed in the presence of a $\mathrm{Pd}-\mathrm{Ag}$ catalyst system, and extensive investigations on the construction of quaternary carbon centers via the intramolecular Heck reaction were carried out. Overman and co-workers first reported the intramolecular 


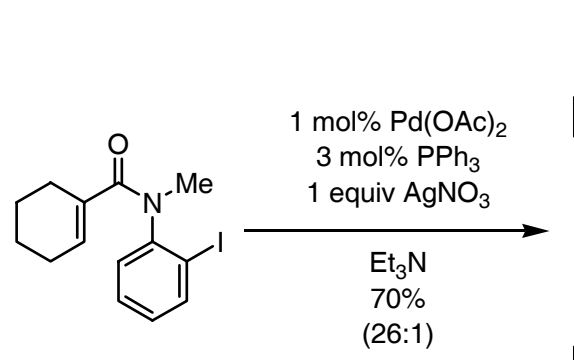

$(26: 1)$

Scheme 1.21<smiles>CN1C(=O)C2(C=CCCC2)c2ccccc21</smiles>

minor

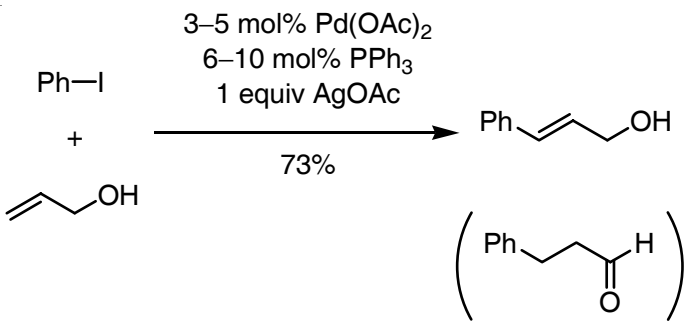

Scheme 1.22

Heck reaction using a combination of a catalytic amount of $\mathrm{Pd}(\mathrm{OAc})_{2} / \mathrm{PPh}_{3}$ complex and a stoichiometric amount of $\mathrm{AgNO}_{3}$, as indicated in Scheme 1.21. Shibasaki and co-workers [28] demonstrated for the first time that an enantioselective intramolecular Heck reaction could be achieved by utilizing a catalytic amount of $\mathrm{Pd}(\mathrm{OAc})_{2} /(R)$-BINAP with a stoichiometric amount of $\mathrm{Ag}_{2} \mathrm{CO}_{3}$ (Scheme 1.23). The Heck reaction in the presence of an Ag salt is proposed to proceed through a cationic pathway. The role of the Ag salt is to abstract the halide ion from the palladium intermediate to leave a vacant site for coordination of the alkene. Grigg and coworkers [29] reported that the addition of a $\mathrm{Tl}^{\mathrm{I}}$ salt instead of an $\mathrm{Ag}^{\mathrm{I}}$ salt led to a similar effect.

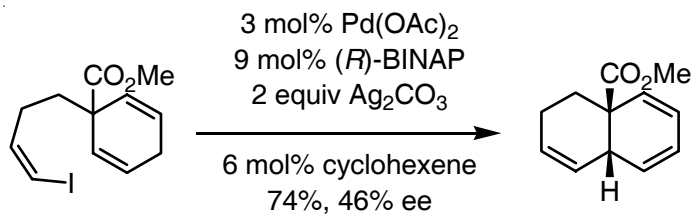

Scheme 1.23

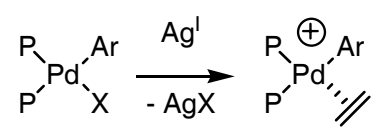




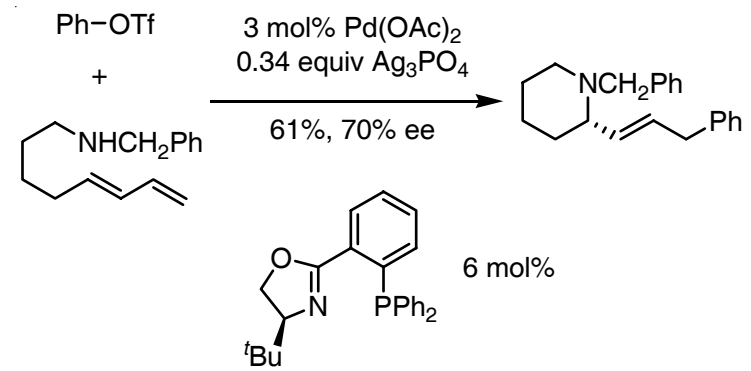

Scheme 1.24

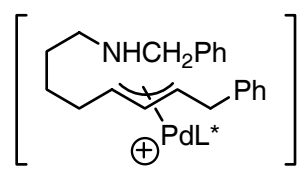

A silver salt is often utilized in enantioselective tandem reactions involving the Heck reaction. For example, Helmchen et al. [30] reported the synthesis of chiral piperidine derivatives through the Heck reaction and subsequent asymmetric allylic amination of the resulting $\pi$-allylpalladium intermediate (Scheme 1.24). The addition of a stoichiometric amount of an Ag salt proved essential to achieve high enantioselectivity. Larock and co-workers [31] reported the asymmetric heteroannulation of allenes using functionalized aryl iodides (Scheme 1.25).

Scheme 1.25

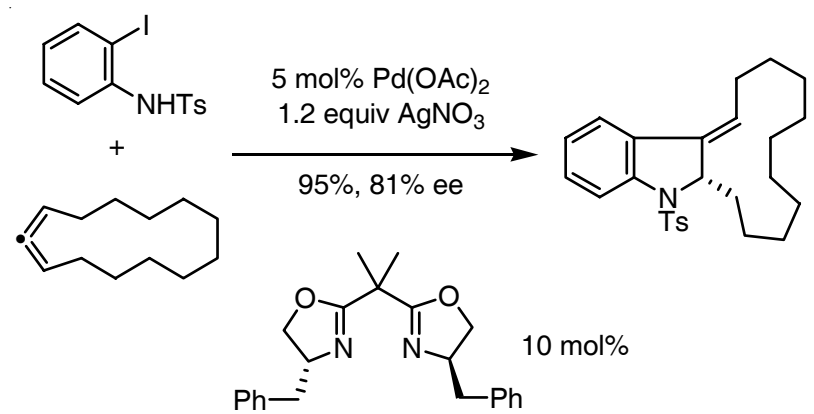

1.2.4

Reactions Involving $\pi$-Allylpalladium Intermediates

\subsubsection{Electrophilic Reactions}

Poli and co-workers [32] applied a $\mathrm{Pd}_{2}(\mathrm{dba})_{3} / \mathrm{PPh}_{3}$ and $\mathrm{Ti}\left(\mathrm{O}^{i} \mathrm{Pr}\right)_{4}$ bimetallic catalyst system to the allylation of active methylene compounds (Scheme 1.26). They investigated the reactions between allyl acetates and various carbon nucleophiles. The $\mathrm{Ti}$ additive coordinates to the nucleophiles and produces titanium enolates after deprotonation. The $\mathrm{p} K_{\mathrm{a}}$ value of the active methylene compound is lowered by the coordination of the Ti additive, making it more reactive. Accordingly, a wide range of nucleophilic agents can be used as reaction partners with $\pi$-allylpalladium 
Scheme 1.26
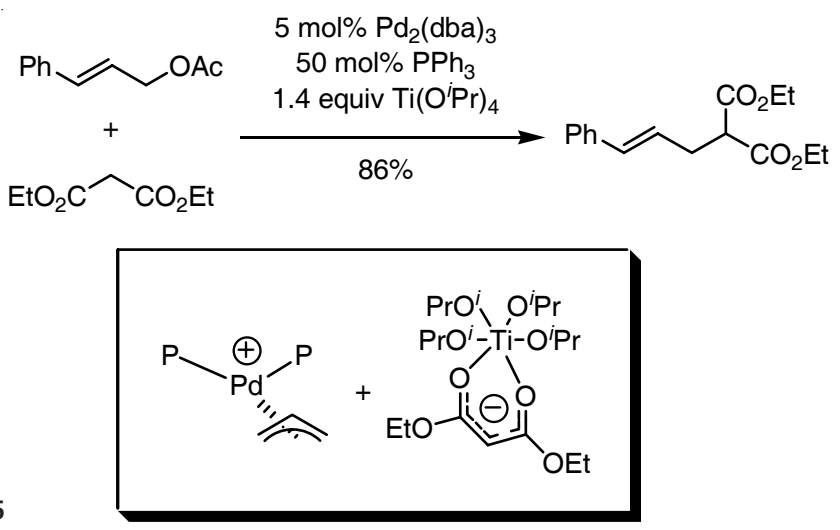

complexes in the presence of the Pd-Ti catalyst system. Applying this methodology to the intramolecular reaction, these authors were able to obtain 2,3-disubstituted pyrrolidinones (Scheme 1.27).

Fuji and co-workers [33] used $\mathrm{Et}_{2} \mathrm{Zn}$ as a base in a palladium-catalyzed asymmetric allylic alkylation reaction (Scheme 1.28). They found that the use of a combination of $\left[\left(\eta^{3}-\mathrm{C}_{3} \mathrm{H}_{5}\right) \mathrm{PdCl}\right]_{2} /(R)$-BINAP and a stoichiometric amount of $\mathrm{Et}_{2} \mathrm{Zn}$ led to a remarkable enhancement of the enantiomeric excess. In contrast to $\mathrm{Et}_{2} \mathrm{Zn}$, the use of bases such as $\mathrm{KH}, \mathrm{NaH}$, $\mathrm{LiH}$, and BuLi resulted in low enantioselectivities.

Scheme 1.27<smiles>CC(=O)OC/C=C\CN(Cc1ccccc1)C(=O)COC(C)=O</smiles><smiles>C=C[C@H]1CN(Cc2ccccc2)C(=O)[C@H]1C(C)=O</smiles><smiles>COC(=O)CC(=O)OC</smiles>

$2 \mathrm{~mol} \%\left[\left(\eta^{3}-\mathrm{C}_{3} \mathrm{H}_{5}\right) \mathrm{PdCl}\right]_{2}$ $8 \mathrm{~mol} \%(R)$-BINAP 2 equiv $\mathrm{Et}_{2} \mathrm{Zn}$

$84 \%, 99 \%$ ee<smiles>COC(=O)C(C(=O)OC)C(/C=C/c1ccccc1)c1ccccc1</smiles>

Scheme 1.28

\subsubsection{Nucleophilic Reactions}

It is well known that $\pi$-allylpalladium intermediates generally behave as allyl cation equivalents and they are widely used for the allylation of various nucleophiles. The reactivity of $\pi$-allylpalladium intermediates can be switched from the ordinary electrophilic one to nucleophilic reactivity when they are combined with a stoichiometric amount of an appropriate metal reagent. 
Inanaga and co-workers [34] found that reactions of allyl acetates with ketones in the presence of a combination of catalytic $\mathrm{Pd}\left(\mathrm{PPh}_{3}\right)_{4}$ and a stoichiometric amount of $\mathrm{SmI}_{2}$ produced homoallylic alcohols (Scheme 1.29). Under these conditions, however, aromatic and $\alpha, \beta$-unsaturated carbonyl compounds could not be used because pinacol-type self-coupling products were obtained predominantly.

Scheme 1.29

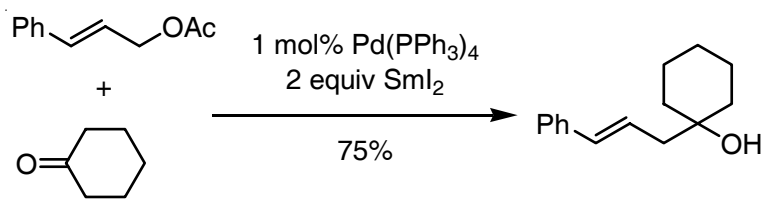

Masuyama and co-workers [35] reported a similar type of reaction using $\mathrm{Pd}\left(\mathrm{PPh}_{3}\right)_{4}$ combined with a stoichiometric amount of $\mathrm{Zn}$ powder (Scheme 1.30). Aromatic and $\alpha, \beta$-unsaturated aldehydes could be used with this $\mathrm{Pd}-\mathrm{Zn}$ system.

Scheme 1.30

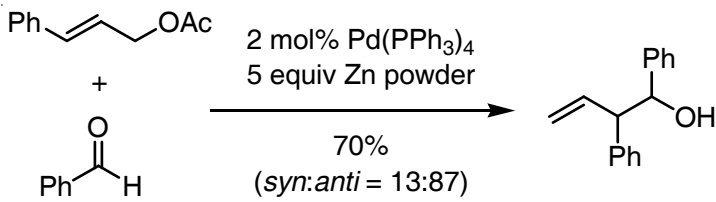

Masuyama and co-workers [36] also developed a new catalyst combination, $\mathrm{PdCl}_{2}(\mathrm{PhCN})_{2}$ and $\mathrm{SnCl}_{2}$, for charge reversal of the $\pi$-allylpalladium complex derived from allyl alcohols (Scheme 1.31). An NMR study revealed that the actual allylating agent was an allyltrichlorotin species.

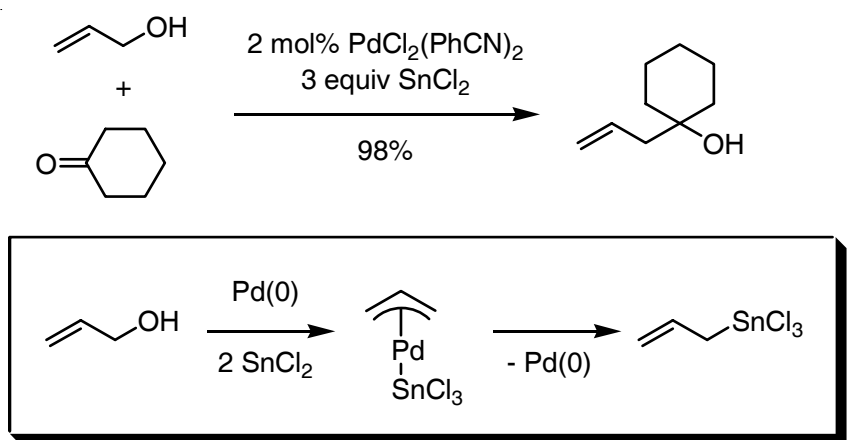

\section{Scheme 1.31}

Tamaru and co-workers [37] investigated the umpolung of $\pi$-allylpalladium complexes via an alkyl-allyl exchange reaction using a stoichiometric amount of $\mathrm{Et}_{2} \mathrm{Zn}$ (Scheme 1.32). The reaction is proposed to involve the in situ formation of allylzinc species by transmetalation between a $\pi$-allylpalladium benzoate and $\mathrm{Et}_{2} \mathrm{Zn}$. 
Scheme 1.32
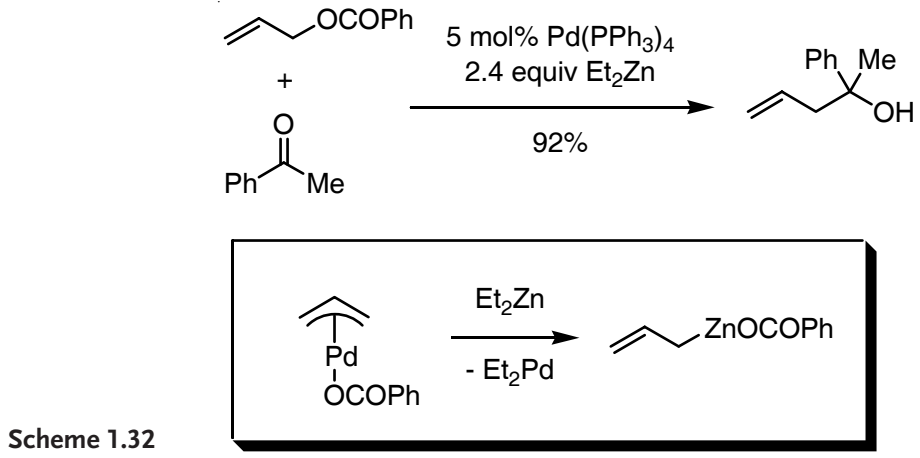

A wide variety of carbonyl compounds, such as aldehydes, ketones, esters, lactones, and acid anhydrides, are applicable under these allylation conditions. The same authors also succeeded in allylating aldehydes by using a combination of $\mathrm{Pd}\left(\mathrm{PPh}_{3}\right)_{4}$ catalyst and a stoichiometric amount of $\mathrm{Et}_{3} \mathrm{~B}$ (Scheme 1.33) [38]. In this case, allylborane would be produced as a nucleophilic agent in situ.

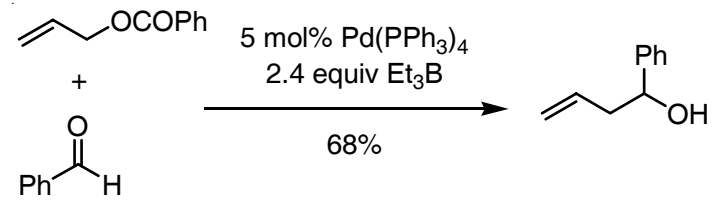

Scheme 1.33

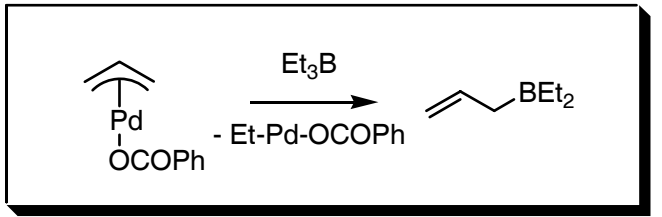

Araki and co-workers [39] applied a combination of $\mathrm{Pd}\left(\mathrm{PPh}_{3}\right)_{4}$ catalyst and a stoichiometric amount of InI for charge reversal of the $\pi$-allylpalladium complexes generated from allyl acetates (Scheme 1.34). Here, allylindium(III) species are generated by reductive transmetalation of a $\pi$-allylpalladium complex with the $\operatorname{In}^{\mathrm{I}}$ salt. A similar catalyst combination, $\mathrm{Pd}(\mathrm{OAc})_{2} /(2 \text {-furyl })_{3} \mathrm{P}$ and In powder, was applied in the three-component coupling reaction of aryl iodides, allenes, and aldehydes by Kang and co-workers [40] (Scheme 1.35). Here, a $\pi$-allylpalladium intermediate was formed by the Heck reaction of aryl iodides with allenes and the intramolecular allylation of aldehydes afforded the cyclic compounds in good yields.

Oppolzer and co-workers [41] reported cyclization through palladium-catalyzed zinc-ene reactions (Scheme 1.36). These reactions also involved transmetalation between $\pi$-allylpalladium intermediates and $\mathrm{Et}_{2} \mathrm{Zn}$ to form the nucleophilic allyl zinc species. Cyclization via the zinc-ene reaction, followed by trapping with $\mathrm{I}_{2}$, afforded the cyclized product. 

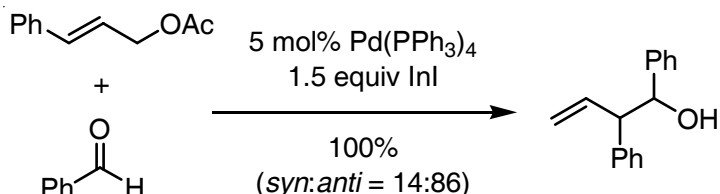

(syn:anti $=14: 86)$

Scheme 1.34

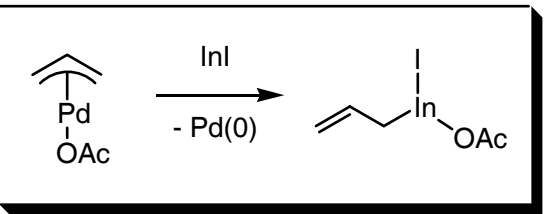

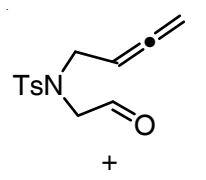

$\mathrm{Ph}-\mathrm{I}$

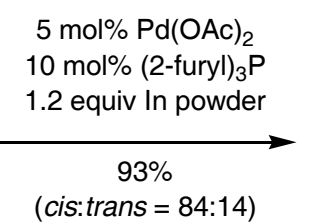<smiles>C=C(c1ccccc1)C1CN([AlH2])CC1O</smiles>

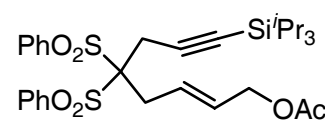

(1) $5 \mathrm{~mol} \% \mathrm{Pd}\left(\mathrm{PPh}_{3}\right)_{4}$ 5 equiv $\mathrm{Et}_{2} \mathrm{Zn}$

(2) $\mathrm{I}_{2}$

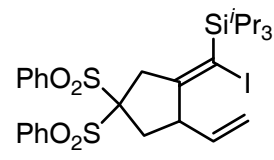

$81 \%$

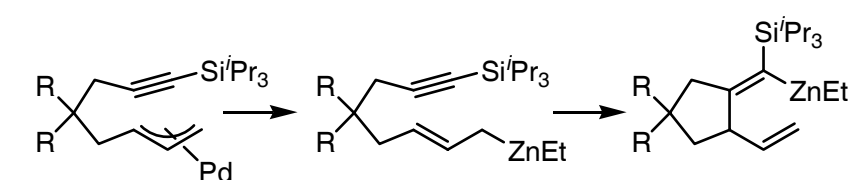

Scheme 1.36

We developed a different protocol to generate a nucleophilic $\pi$-allylpalladium species and succeeded in the allylation of various aldehydes and imines (Scheme 1.37) [42]. The reactions of allylstannanes with aldehydes or imines in the presence of a catalytic amount of $\mathrm{PdCl}_{2}\left(\mathrm{PPh}_{3}\right)_{2}$ afforded the corresponding homoallyl alcohols or amines in high yields. The key is to generate a bis- $\pi$-allylpalladium complex, which acts as a characteristic nucleophilic agent. Catalytic asymmetric allylation of imines has been achieved using the chiral $\pi$-allylpalladium chloride dimer as a source of the palladium catalyst [43]. More recently, it has been reported that in the presence of water the chemical yields and enantioselectivities of catalytic asymmetric 


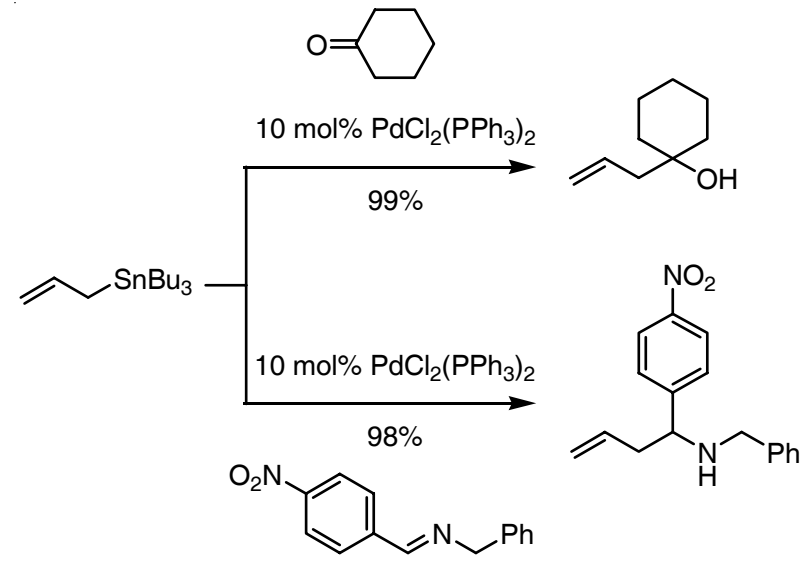

Scheme 1.37
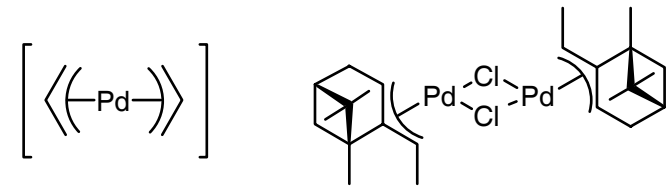

allylations of imines were enhanced, the latter up to $91 \%$ ee [44]. Not only allylstannanes but also allylsilanes can be used as a nucleophilic allyl source (Scheme 1.38) [45], and in the presence of a chiral palladium catalyst the asymmetric allylation takes place smoothly giving high yields and high ee values.

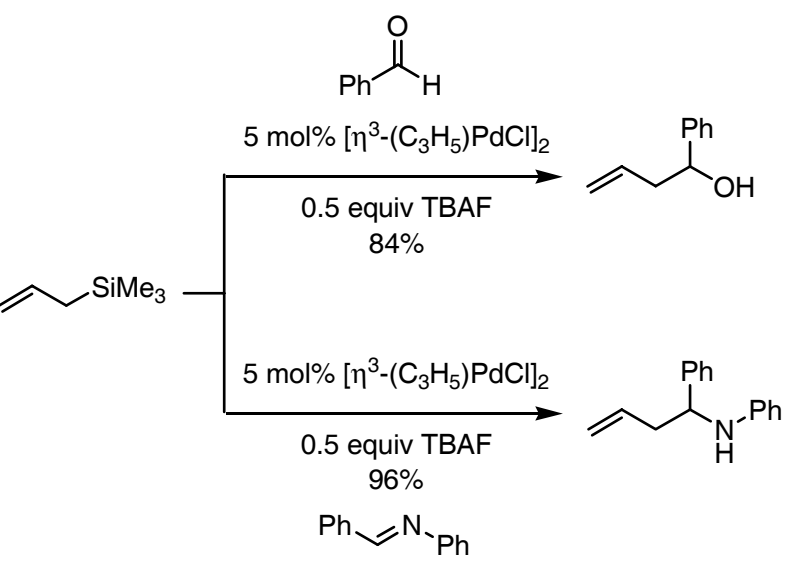

Scheme 1.38

$$
\mathrm{Ph}=\mathrm{N}_{-\mathrm{Ph}}
$$


1.2 .5

\section{Nickel-Catalyzed Three-Component Coupling Reaction}

Mori and co-workers [46] developed a stereoselective cyclization involving a $\pi$-allylnickel complex generated from a 1,3-diene and a hydride nickel complex (Scheme 1.39). The combination of a catalytic amount of $\mathrm{Ni}(\operatorname{cod})_{2} / \mathrm{PPh}_{3} \mathrm{complex}$ and a stoichiometric amount of $\mathrm{Et}_{3} \mathrm{SiH}$ is the key to generating the active hydride nickel species, insertion of the 1,3-diene moiety into which affords a $\pi$-allylnickel intermediate. The cyclization takes place in a stereoselective manner.

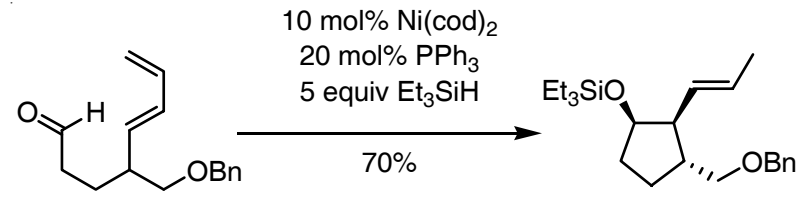

Scheme 1.39

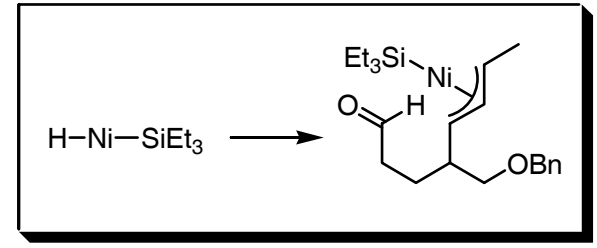

Tamaru and co-workers investigated the intermolecular homoallylation of aldehydes with 1,3-dienes. They developed two catalytic systems; one is a combination of a catalytic amount of $\mathrm{Ni}(\mathrm{acac})_{2}$ and a stoichiometric amount of $\mathrm{Et}_{3} \mathrm{~B}$ (Scheme 1.40) [47], and the other is a combination of a Ni(acac) ${ }_{2}$ catalyst with $\mathrm{Et}_{2} \mathrm{Zn}$ (Scheme 1.41) [48]. Both systems were found to promote the homoallylation of aldehydes with high regio- and stereoselectivity. The two catalyst systems show complementary reactivities. The $\mathrm{Ni}-\mathrm{Et}_{3} \mathrm{~B}$ system is effective for reactive carbonyl compounds such as aromatic and $\alpha, \beta$-unsaturated aldehydes, whereas the $\mathrm{Ni}-\mathrm{Et}_{2} \mathrm{Zn}$ combination is effective for saturated aldehydes and ketones. A proposed mechanism involves nucleophilic addition of diene-nickel(0) complexes to carbonyl compounds coordinated by $\mathrm{Et}_{2} \mathrm{Zn}$ (or $\mathrm{Et}_{3} \mathrm{~B}$ ) and ethyl group migration from $\mathrm{Zn}$ to $\mathrm{Ni}$ to form a $\pi$-allylnickel intermediate. Subsequent $\beta$-hydrogen elimination from the Et group and reductive elimination furnishes the product and ethylene with regeneration of the $\mathrm{Ni}^{0}$ catalyst.

Scheme 1.40

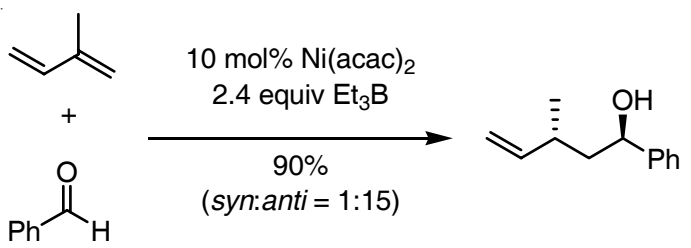



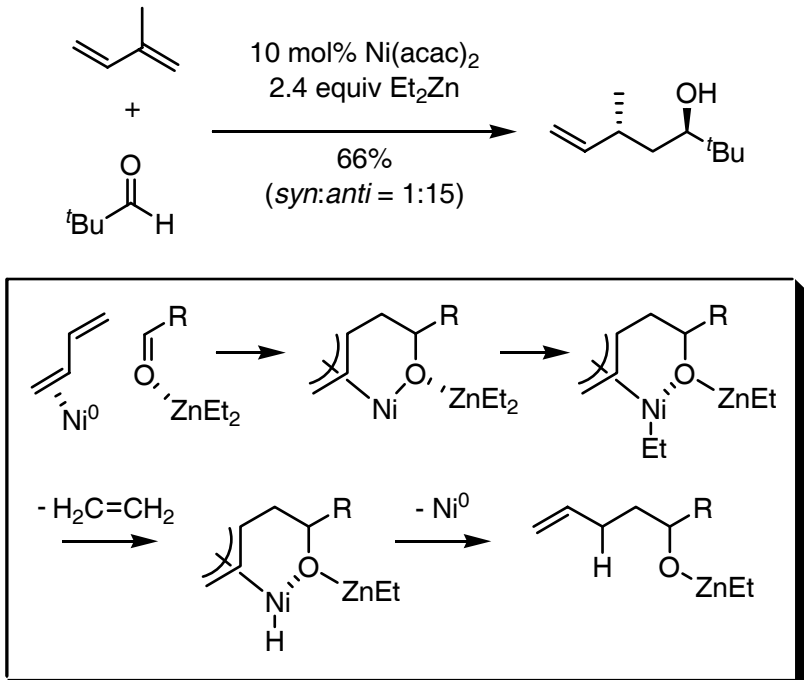

Scheme 1.41

Montgomery and co-workers employed a similar combination as a catalyst system, specifically a catalytic amount of $\mathrm{Ni}(\mathrm{cod})_{2}$ and a stoichiometric amount of $\mathrm{Me}_{2} \mathrm{Zn} /$ $\mathrm{MeZnCl}$, for the alkylative cyclization of alkynyl enones (Scheme 1.42) [49] and of alkynyl aldehydes (Scheme 1.43) [50]. They also succeeded in cyclizing alkynyl enones with a $\mathrm{Ni}-\mathrm{AlMe}_{3}$ system [51], and in cyclizing alkynyl ketones with a $\mathrm{Ni}-\mathrm{Et}_{3} \mathrm{SiH}$ system [52].

Scheme 1.42<smiles>C#CCCC/C=C/C(=O)c1ccccc1</smiles>
1 equiv $\mathrm{Me}_{2} \mathrm{Zn} / \mathrm{MeZnCl}$

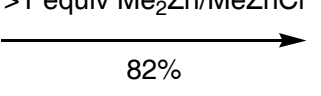<smiles>C/C=C1/CCCC1CC(=O)c1ccccc1</smiles>

Scheme 1.43
$5.5 \mathrm{~mol} \% \mathrm{Ni}(\mathrm{cod})_{2}$ $>1$ equiv $\mathrm{Me}_{2} \mathrm{Zn} / \mathrm{MeZnCl}$ $70 \%$<smiles>C/C=C1/CCCC1O</smiles>

Catalytic asymmetric reductive coupling of alkynes and aldehydes was investigated by Jamison and co-workers [53] utilizing a stoichiometric amount of $\mathrm{Et}_{3} \mathrm{~B}$ and a catalytic amount of $\mathrm{Ni}(\mathrm{cod})_{2}$ combined with a chiral phosphine ligand (Scheme 1.44). High regioselectivity and enantioselectivity were observed. The same authors also employed imines instead of aldehydes to synthesize allylamine derivatives (Scheme 1.45) [54]. The asymmetric reaction using (+)-neomenthyldiphenylphosphine ((+)-NMDPP) resulted in moderate enantioselectivities. Homoallyl alcohols have 

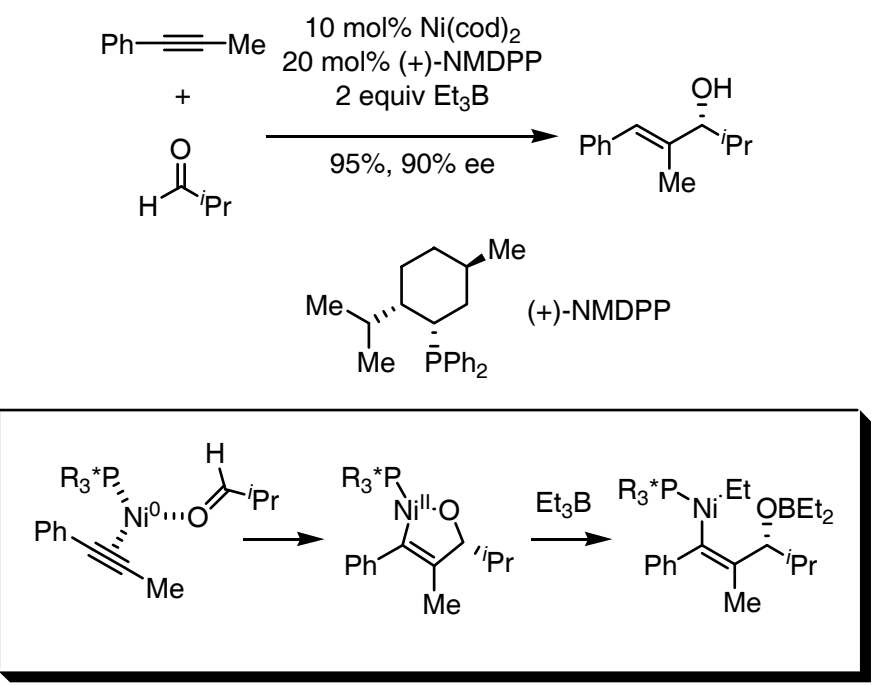

Scheme 1.44

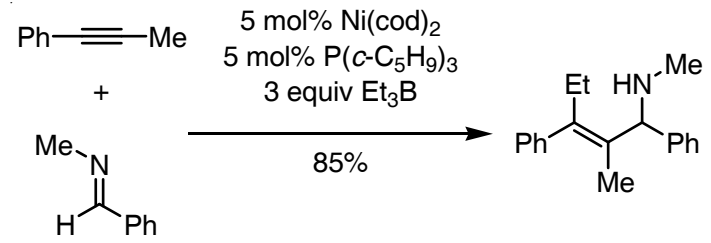

Scheme 1.46

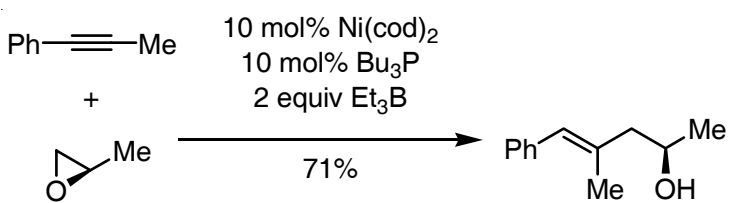

been synthesized by carrying out the reactions between alkynes and epoxides in the presence of a catalytic amount of $\mathrm{Ni}(\mathrm{cod})_{2} / \mathrm{Bu}_{3} \mathrm{P}$ and a stoichiometric amount of $\mathrm{Et}_{3} \mathrm{~B}$ (Scheme 1.46) [55].

\subsection{6}

\section{The Nozaki-Hiyama-Kishi Reaction}

Nozaki and co-workers [56] first reported the addition of vinyl halides to aldehydes in the presence of a stoichiometric amount of $\mathrm{CrCl}_{2}$, but the success of the reaction depended strongly on the nature of the Cr source. Later, Nozaki's and Kishi's groups independently discovered that this reaction could be effectively promoted by the 

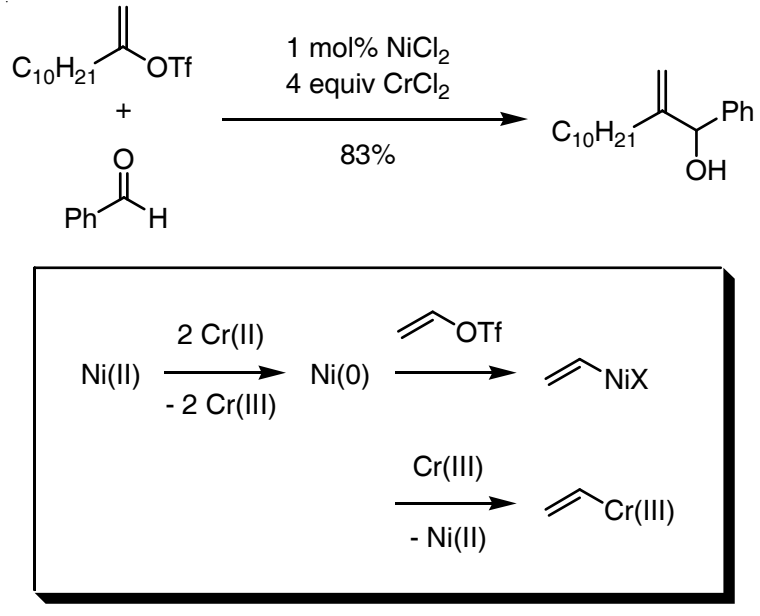

Scheme 1.47

addition of a catalytic amount of $\mathrm{NiCl}_{2}$ or $\mathrm{Pd}(\mathrm{OAc})_{2}$ (Scheme 1.47) [57]. The active nucleophilic species is proposed to be a vinylchromium(III) species generated by transmetalation between the vinylnickel intermediate and $\mathrm{Cr}^{\mathrm{III}}$ salt. The $\mathrm{Cr}^{\mathrm{II}}$ salt also acts as a reductant for $\mathrm{Ni}^{\mathrm{iI}}$ to generate an $\mathrm{Ni}^{0}$ catalyst.

Fürstner et al. [58] reported that the use of catalytic amounts of $\mathrm{NiCl}_{2}$ and $\mathrm{CrCl}_{2}$ was sufficient for the above transformations when the reactions were carried out in the presence of stoichiometric amounts of $\mathrm{Mn}$ powder and $\mathrm{Me}_{3} \mathrm{SiCl}$ (Scheme 1.48). The $\mathrm{Cr}^{\mathrm{III}}$ salt produced at the end of the catalytic cycle was efficiently reduced by $\mathrm{Mn}$ powder to regenerate the active $\mathrm{Cr}^{\mathrm{II}}$ salt. However, the use of stoichiometric amounts of $\mathrm{Mn}$ and $\mathrm{Me}_{3} \mathrm{SiCl}$ proved essential for smooth transformations. An extensive investigation of the asymmetric version of this $\mathrm{Ni}-\mathrm{Cr}$-mediated reaction has recently been carried out by Kishi and co-workers [59].

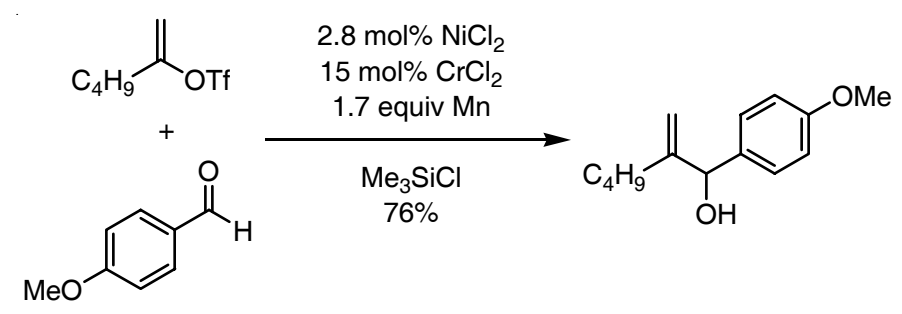

Scheme 1.48 
1.3

Reactions Promoted by a Combination of Catalytic Amounts of Two Metals

1.3.1

Transition Metal Catalyzed Cross-Coupling Reactions

\subsubsection{The Stille Reaction}

The use of an additional metal salt in the cross-coupling reaction has been a widely adopted approach to enhance the reactivity and sometimes the selectivity of the transformation. The use of a $\mathrm{Cu}$ catalyst in combination with a Pd catalyst in the Stille coupling reaction [60] was first investigated by Liebeskind et al. [61] (Scheme 1.49).

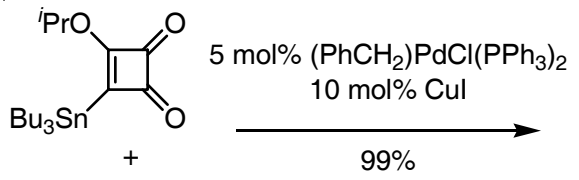

Scheme 1.49

$$
\mathrm{Ph}-\mathrm{I}
$$<smiles>O=c1c(O)c(-c2ccccc2)c1=O</smiles>

They reported therein the cross-coupling of a stannylcyclobutenedione with various aryl iodides in the presence of $\left(\mathrm{PhCH}_{2}\right) \mathrm{PdCl}\left(\mathrm{PPh}_{3}\right)_{2}$ and $\mathrm{CuI}$ catalysts. Using the $\mathrm{Pd}-\mathrm{Cu}$ bimetallic catalyst system, a rate enhancement was observed and the reaction temperature could be lowered. The authors proposed the following two roles for the $\mathrm{Cu}$ additive [62].

First, the Cu catalyst most probably scavenges free phosphine ligand, which retards transmetalation (Eq. 1.1). When triphenylphosphine was used as a ligand for the Pd catalyst, addition of the $\mathrm{Cu}$ catalyst led to a rate enhancement as compared to the traditional Stille coupling conditions. On the other hand, little effect was observed when the $\mathrm{Cu}$ additive was used in the presence of a soft ligand such as triphenylarsine $\left(\mathrm{AsPh}_{3}\right)$, which did not inhibit the ligand dissociation from the Pd center.

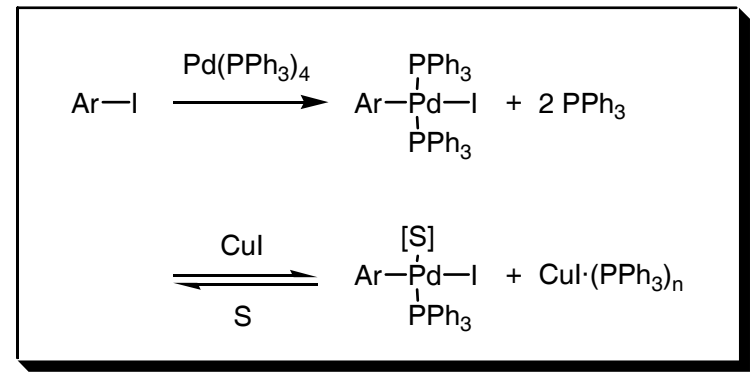

Second, the $\mathrm{Cu}$ catalyst probably generates an organocopper species in highly polar solvents such as NMP and DMF in the absence of strongly coordinating ligands (Eq. 1.2). The transmetalation between the Pd intermediate and the derived organocopper species proceeds more easily than the transmetalation with the organostannane itself. 


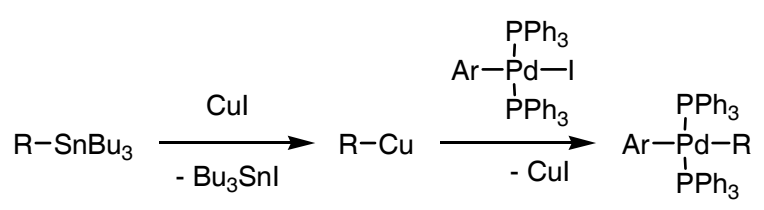

Recently, Cho and co-workers [63] reported on regioselective Stille couplings of 3,5-dibromo-2-pyrone. The reaction in the presence of catalytic amounts of $\mathrm{Pd}\left(\mathrm{PPh}_{3}\right)_{4}$ and $\mathrm{CuI}$ in toluene produced 5-bromo-3-phenyl-2-pyrone (Scheme 1.50a), whereas the reaction in the presence of catalytic $\mathrm{Pd}\left(\mathrm{PPh}_{3}\right)_{4}$ and a stoichiometric amount of CuI in DMF furnished 3-bromo-5-phenyl-2-pyrone (Scheme 1.50b).

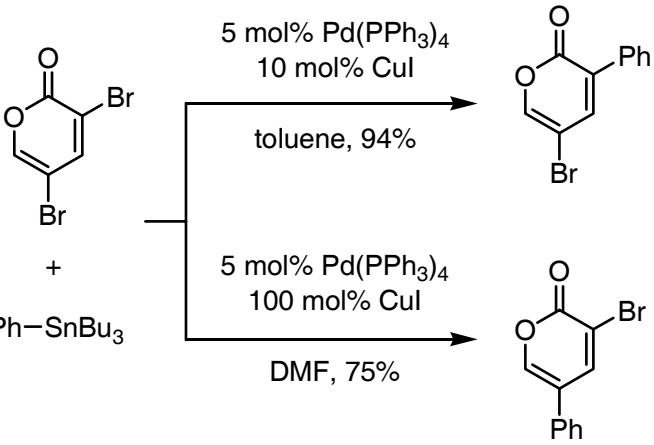

\section{Scheme 1.50}

Flack and co-workers [64] employed a combination of $\mathrm{PdCl}_{2}\left(\mathrm{PPh}_{3}\right)_{2}$ and $\mathrm{CuCN}$ catalysts for the reaction between acyl chlorides and $\alpha$-heteroatom-substituted stannanes and investigated the stereoselectivity of the coupling reaction (Scheme 1.51). The reaction proceeded with retention of configuration.

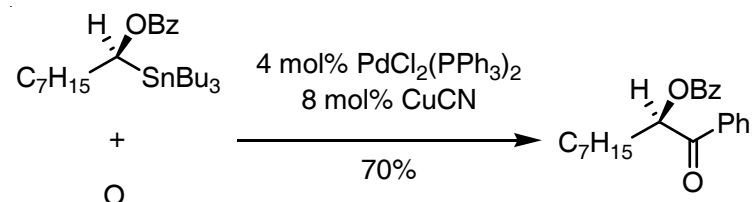

\subsubsection{The Hiyama Reaction}

Mori and Hiyama et al. [65] developed the cross-coupling reaction of alkynylsilanes with aryl or alkenyl triflates in the presence of a combination of $\mathrm{Pd}\left(\mathrm{PPh}_{3}\right)_{4}$ and $\mathrm{CuCl}$ catalysts (Scheme 1.52). This is a new type of the reaction between $\mathrm{sp}^{2}$ - and sp-hybridized carbon centers. The similar coupling reaction between aryl halides and terminal alkynes is known as the Sonogashira reaction; however, alkynylsilanes 


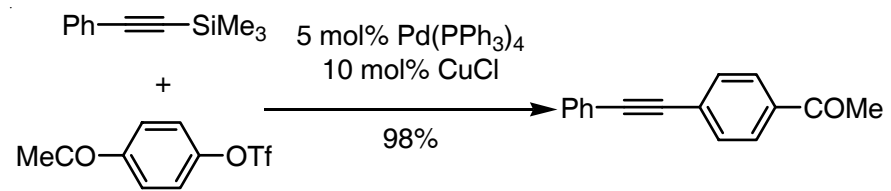

Scheme 1.52

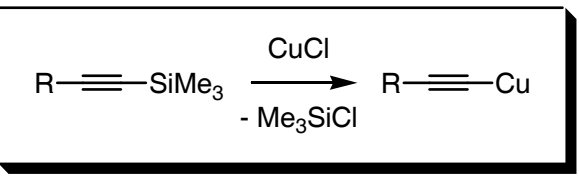

are inert under the corresponding conditions. The role of the $\mathrm{Cu}$ additive is to generate a reactive alkynylcopper species by transmetalation from silicon to copper in polar solvents such as DMF [66].

\subsubsection{The Sonogashira Reaction}

The cross-coupling reaction between terminal alkynes and aryl or vinyl halides was developed by Sonogashira and Hagihara et al. [67] (Scheme 1.53). The reaction was found to proceed smoothly under catalysis by a combination of $\mathrm{PdCl}_{2}\left(\mathrm{PPh}_{3}\right)_{2}$ and $\mathrm{CuCl}$ in the presence of $\mathrm{Et}_{2} \mathrm{NH}$. The role of the Pd catalyst is to form aryl- or vinyl-palladium species by oxidative insertion into the carbon-halogen bond, and the role of the $\mathrm{Cu}$ catalyst is to generate a copper-acetylide to facilitate transmetalation with the Pd intermediate. The effect of the amine has also been thoroughly investigated and cyclic amines such as piperidine and pyrrolidine were found to increase the rate of transformation [68].

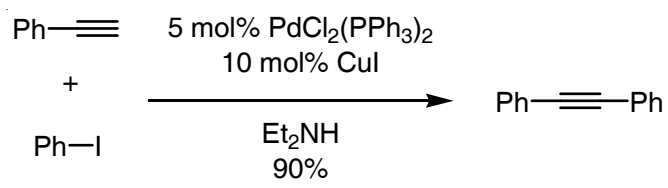

Scheme 1.53

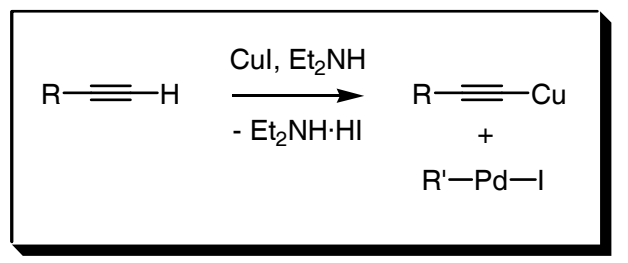

The effect of additional additives was also surveyed and the optimal combination of catalysts was found to depend on the starting materials. When an alkynyl epoxide was used as a coupling partner with vinyl triflate, a combination of $\mathrm{Pd}\left(\mathrm{PPh}_{3}\right)_{4}$ and AgI gave better results than a Pd-Cu bimetallic catalyst (Scheme 1.54) [69]. Several $\mathrm{ZnX}_{2}$ salts were examined as co-catalysts, although a stoichiometric amount of $\mathrm{ZnX}_{2}$ was usually needed to obtain high yields of adducts [70]. 


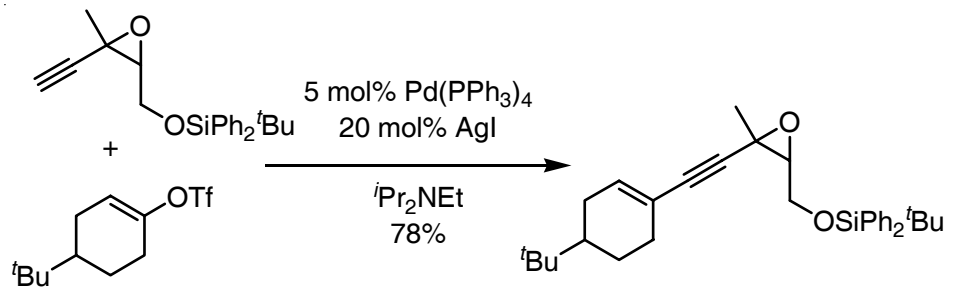

Scheme 1.54

The construction of complicated cyclic compounds is often accomplished through sequential reactions involving a Sonogashira coupling ( $\mathrm{Pd}-\mathrm{Cu}$ bimetallic system), where the cross-coupling reaction takes place with concomitant cyclization. We reported the synthesis of benzopyranone derivatives by the reaction of vinyl bromides with terminal alkynes under catalysis by $\mathrm{Pd}\left(\mathrm{PPh}_{3}\right)_{4}$ and $\mathrm{CuI}$ (Scheme 1.55) [71].

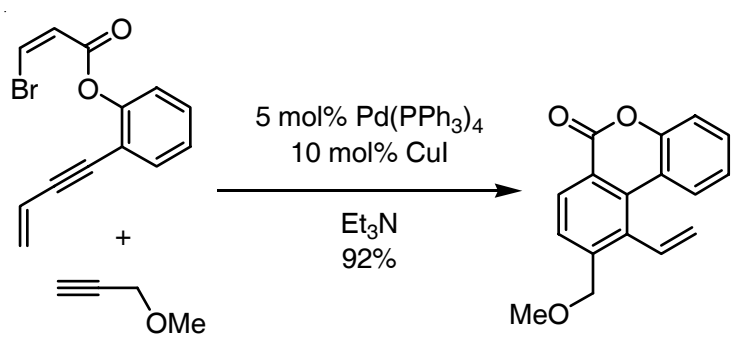

Scheme 1.55

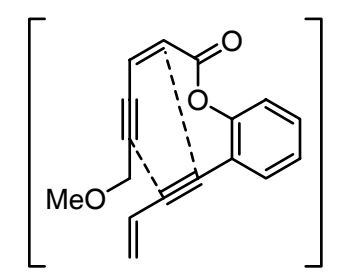

The initial Sonogashira coupling reaction afforded an intermediate bearing two conjugated enyne moieties, and subsequent palladium-catalyzed intramolecular benzannulation produced the tricyclic adduct. Cacchi and co-workers [72] reported the synthesis of benzofuran derivatives through the coupling of terminal alkynes with 2-iodophenols in the presence of $\mathrm{Pd}(\mathrm{OAc})_{2}\left(\mathrm{PPh}_{3}\right)_{2}$ and $\mathrm{CuI}$ as a bimetallic catalyst system (Scheme 1.56). The reaction proceeds through the formation of the 2-alkynylphenol intermediate. Yamanaka and co-workers [73] succeeded in synthesizing indoles from terminal alkynes and $\mathrm{N}$-(2-iodophenyl)methanesulfonamide by employing a $\mathrm{Pd}-\mathrm{Cu}$ bimetallic catalyst (Scheme 1.57). The presence of the methanesulfonyl group on the nitrogen atom is essential for the spontaneous cyclization to afford the indole skeleton. When 2-iodobenzoic acid was used as a coupling partner for terminal alkynes in the presence of a Pd-Cu bimetallic catalyst, consecutive heteroannulation took place to afford phthalides (Scheme 1.58) [74]. The synthesis of $\gamma$-alkylidene butenolides has also been achieved by $\mathrm{Lu}$ and coworkers [75] employing (Z)-3-bromopropenoic acid as a starting material. 
26| 1 Organic Synthesis with Bimetallic Systems

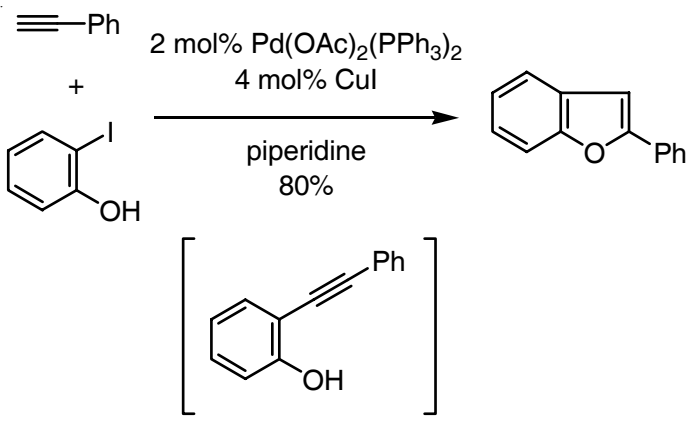

Scheme 1.56

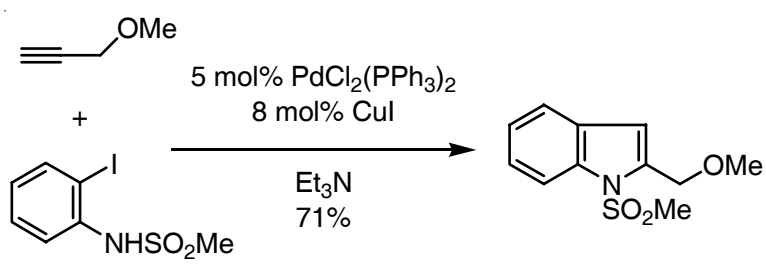

Scheme 1.57

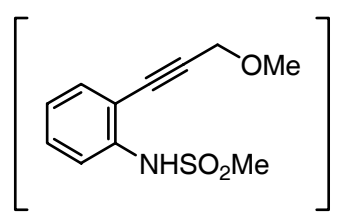

Scheme 1.58
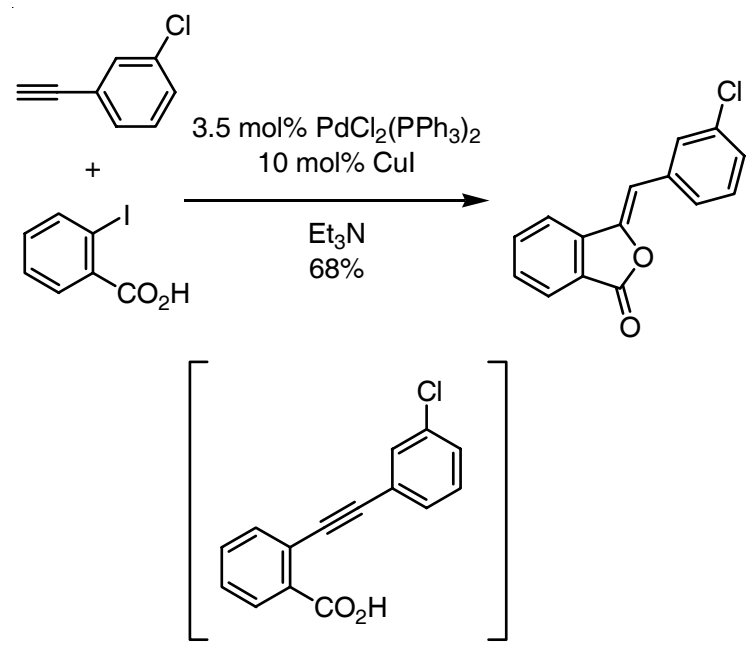
1.3.2

\section{The Wacker Reaction}

Murahashi and Hosokawa et al. [76] reported that the Wacker oxidation could be promoted by a catalytic amount of a $\mathrm{Pd}-\mathrm{Cu}$ catalyst under $\mathrm{O}_{2}$ atmosphere. They found that the $\mathrm{C}-\mathrm{C}$ double bonds of allylamides could be directly oxidized with molecular oxygen in the presence of a catalyst system consisting of $\mathrm{PdCl}_{2}\left(\mathrm{MeCN}_{2}\right.$ and $\mathrm{CuCl}$ together with hexamethylphosphoric triamide (HMPA) as an additive (Scheme 1.59). The oxidation proceeded in a regioselective manner to afford aldehydes from $\mathrm{N}$-allylamides, which is in sharp contrast to the usual Wacker oxidation giving methyl ketones. It is proposed that the oxidation is caused by a $\mathrm{Pd}-\mathrm{OOH}$ species derived from a hydridepalladium intermediate $(\mathrm{Pd}-\mathrm{H})$ and molecular oxygen $\left(\mathrm{O}_{2}\right)$. This hydridepalladium intermediate would be generated in situ by chloropalladation of the alkene followed by $\beta$-elimination. The role of the $\mathrm{Cu}$ catalyst can be envisaged as one of accelerating the formation of the active $\mathrm{Pd}-\mathrm{OOH}$ species from the $\mathrm{Pd}-\mathrm{H}$ species in the presence of HMPA.

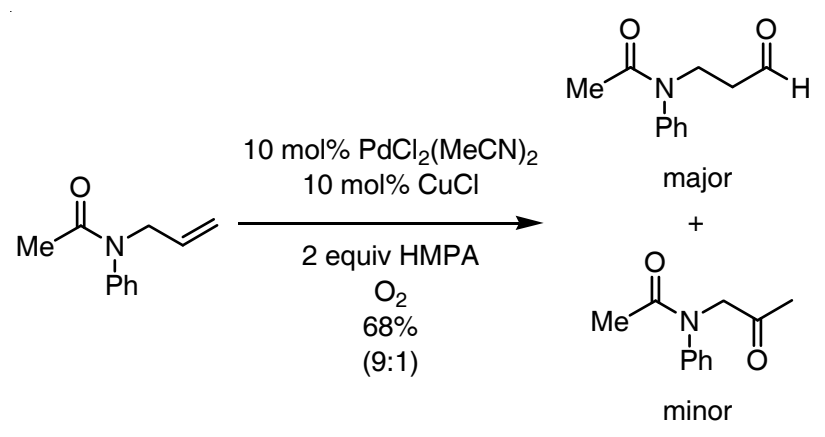

Scheme 1.59

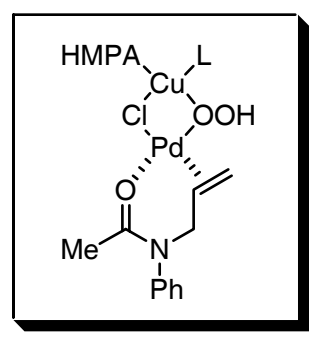

The same authors also succeeded in aminating alkenes in the presence of a combination of $\mathrm{PdCl}_{2}$ and $\mathrm{CuCl}$ catalysts under $\mathrm{O}_{2}$ atmosphere (Scheme 1.60) [77]. Alkenes having an electron-withdrawing group and styrene could be used as substrates. Stahl and co-workers [78] investigated similar reactions between styrene derivatives and amides and found that the regioselectivity was changed on addition of catalytic amounts of bases such as $\mathrm{Et}_{3} \mathrm{~N}$ and $\mathrm{NaOAc}$ (Scheme 1.61). In this case, Markovnikov-type adducts were obtained exclusively. 
28 1 Organic Synthesis with Bimetallic Systems<smiles>O=C1NCCO1</smiles>

$+$

$\otimes^{R}$

Scheme 1.60

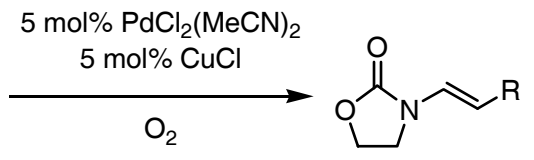

$\mathrm{R}=\mathrm{CO}_{2} \mathrm{Me} \quad 84 \%$

$\mathrm{Ph} \quad 40 \%$<smiles>O=C1NCCO1</smiles>

$+$ $\otimes^{P h}$

\section{$5 \mathrm{~mol} \% \mathrm{PdCl}_{2}(\mathrm{MeCN})_{2}$ $5 \mathrm{~mol}_{0} \mathrm{CuCl}_{2}$ \\ $10 \mathrm{~mol}_{0} \mathrm{Et}_{3} \mathrm{~N}$}

$\mathrm{O}_{2}$

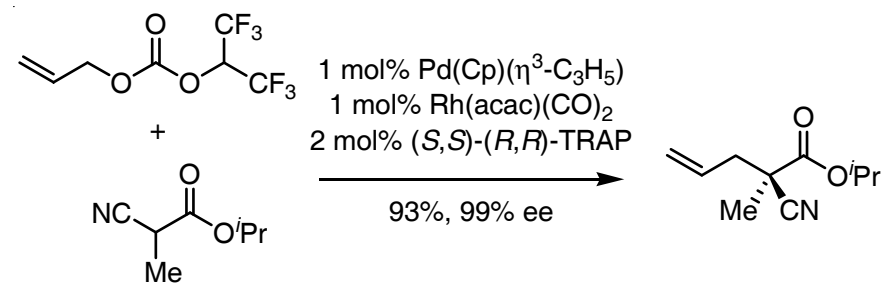

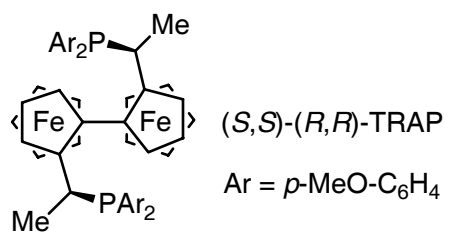

Scheme 1.62

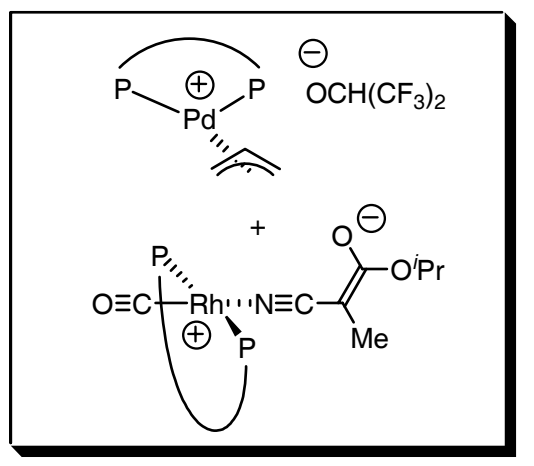


1.3.3

\section{Reactions Involving $\pi$-Allylpalladium Intermediates}

Sawamura and Ito et al. [79] successfully accomplished an enantioselective allylic alkylation reaction by employing a two-component catalyst system consisting of $\mathrm{Rh}(\mathrm{acac})(\mathrm{CO})_{2}$ and $\mathrm{Pd}(\mathrm{Cp})\left(\eta^{3}-\mathrm{C}_{3} \mathrm{H}_{5}\right)$ complexes, combined with $(S, S)-(R, R)-2,2^{\prime \prime}-$ bis[1-(diarylphosphino)ethyl]-1,1"-biferrocene (TRAP) as a trans-chelating chiral phosphine ligand (Scheme 1.62). The use of allyl hexafluoroisopropyl carbonate and active methyne compounds bearing cyano groups as starting materials was essential to obtain the allylated products in high yields and with excellent enantioselectivities. The chiral Rh catalyst coordinates to the cyano group to control the orientation of a prochiral enolate, while the Pd catalyst behaves as a precursor for formation of the $\pi$-allylpalladium species.

Tsuji and co-workers [80] reported the allylation of ketones starting from their enol acetates catalyzed by a combination of $\mathrm{Pd}_{2}(\mathrm{dba})_{3} \cdot \mathrm{CHCl}_{3} / \mathrm{dppe}$ and $\mathrm{Bu}_{3} \mathrm{SnOMe}$ (Scheme 1.63a). When the same reaction was conducted in MeCN, the corresponding $\alpha, \beta$-unsaturated ketones were obtained (Scheme 1.63b) [81]. The key to these transformations is the generation of the corresponding stannyl enolates in situ by the reaction of enol acetates with $\mathrm{Bu}_{3} \mathrm{SnOMe}$. Transmetalation of stannyl enolates with $\pi$-allylpalladium methoxide gives the $\pi$-allylpalladium enolates. Reductive elimination affords the allylated ketones, while $\beta$-hydrogen elimination produces the $\alpha, \beta$-unsaturated ketones as the final products.
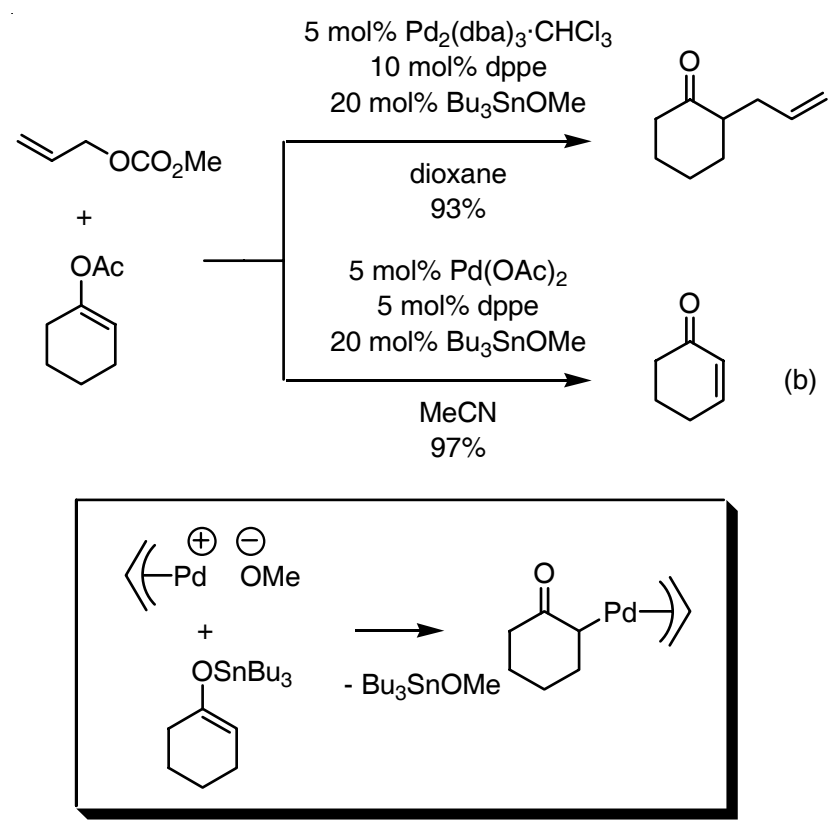

Scheme 1.63 


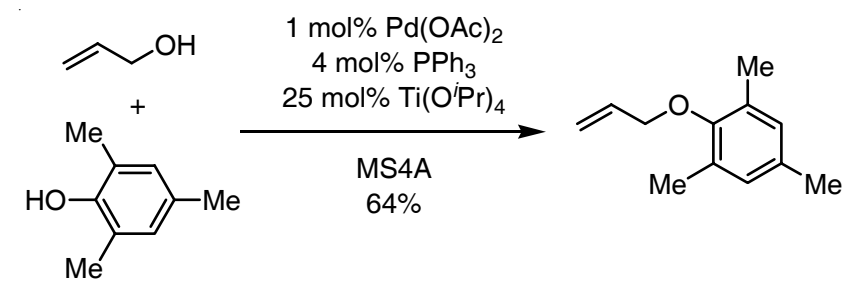

Scheme 1.64

Miura and co-workers employed $\mathrm{Pd}(\mathrm{OAc})_{2} / \mathrm{PPh}_{3}$ and $\mathrm{Ti}\left(\mathrm{O}^{i} \mathrm{Pr}\right)_{4}$ catalysts in the allylic substitution reaction between allyl alcohol and phenols (Scheme 1.64) [82]. Without the addition of the Ti catalyst, the reaction was sluggish and only a low yield of the desired allyl phenyl ether was obtained. Yang et al. [83] applied the same Pd-Ti catalyst system to the reaction between allyl alcohol and anilines (Scheme 1.65). The role of the Ti additive may be the activation of allyl alcohol by forming allyl titanate, thereby facilitating oxidative addition of the $\mathrm{Pd}^{0}$ catalyst. Alternatively, the Ti catalyst may accelerate the ligand exhange between $\pi$-allylpalladium hydroxide and nucleophiles such as phenols and anilines.
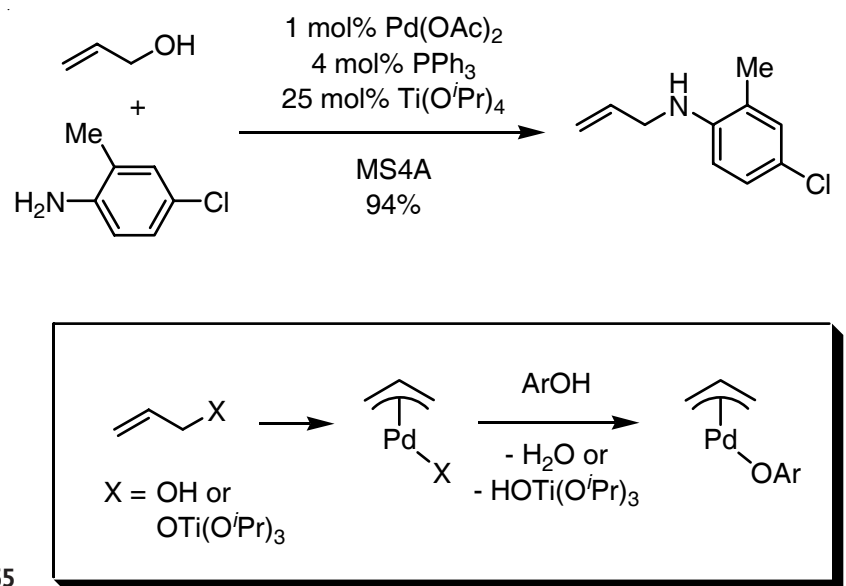

Scheme 1.65

1.3.4

Transition Metal Catalyzed Cyclization Reactions

\subsubsection{1 [3+2] Cycloaddition Reactions}

We developed a synthesis of 1,2,3-triazoles based on $\mathrm{Pd}-\mathrm{Cu}$ bimetallic-catalyzed three-component coupling (TCC) of non-activated alkynes, allyl methyl carbonate, and trimethylsilyl azide (Scheme 1.66). Regioselective formation of 2-allyl-1,2,3triazoles was achieved by carrying out the TCC reaction in the presence of a catalyst system of $\mathrm{Pd}_{2}(\mathrm{dba})_{3} \cdot \mathrm{CHCl}_{3} / \mathrm{P}(\mathrm{OPh})_{3}$ and $\mathrm{CuCl}\left(\mathrm{PPh}_{3}\right)_{3}$ [84]. A regioselective synthesis of 1 -allyl-1,2,3-triazoles was achieved by conducting the TCC reaction 


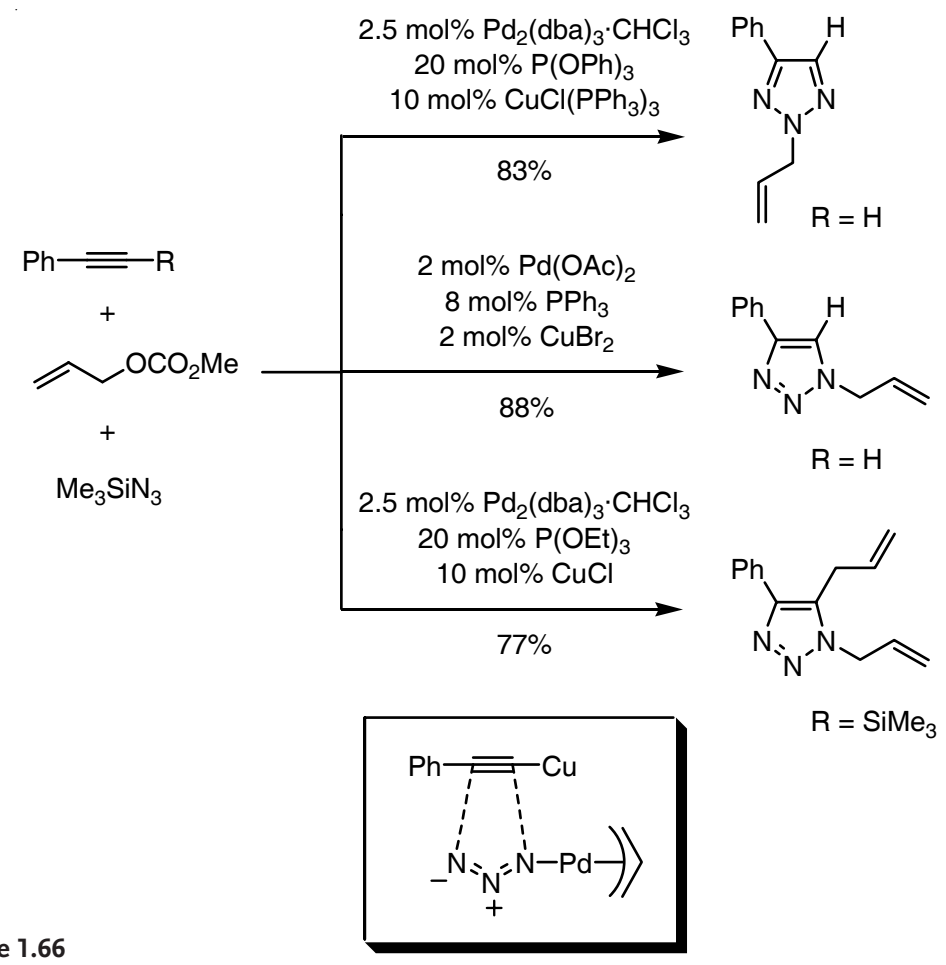

Scheme 1.66

under catalysis by a $\mathrm{Pd}(\mathrm{OAc})_{2} / \mathrm{PPh}_{3}$ and $\mathrm{CuBr}_{2}$ system [85]. When trimethylsilylacetylenes were used as starting materials and the reaction was performed in the presence of $\mathrm{Pd}_{2}(\mathrm{dba})_{3} \cdot \mathrm{CHCl}_{3} / \mathrm{P}(\mathrm{OEt})_{3}$ and $\mathrm{CuCl}$ catalysts, 1,5-diallyltriazoles were formed selectively [86]. The formation of a copper-acetylide, which activates the C-C triple bond of alkynes, and the generation of active azide species such as $\pi$-allylpalladium azide complex and/or allyl azide, are proposed as being involved in the catalytic cycles. [3+2] cycloaddition between the copper-acetylide and the active azide species to afford the triazole framework is believed to be a common feature of all of these transformations.

It is well known that the palladium-trimethylenemethane (Pd-TMM) complex generated from 2-(trimethylsilylmethyl)allyl acetate adds to $\alpha, \beta$-unsaturated carbonyl compounds in a 1,4-addition fashion to produce methylenecyclopentane derivatives. Trost and co-workers found a dramatic change in the chemoselectivity upon the addition of $\mathrm{Bu}_{3} \mathrm{SnOAc}$. A combination of $\mathrm{Pd}(\mathrm{OAc})_{2} / \mathrm{PPh}_{3}$ and $\mathrm{Bu}_{3} \mathrm{SnOAc}$ catalysts promoted 1,2-addition of the Pd-TMM complex to carbonyl compounds and methylenetetrahydrofuran cycloadducts were obtained (Scheme 1.67) [87]. In(acac) was also found to be applicable instead of $\mathrm{Bu}_{3} \mathrm{SnOAc}$ [88]. Two possible roles of the $\mathrm{Sn}$ and In additives have been postulated. One is the stabilization of the alkoxide anion generated after addition of the Pd-TMM complex to the carbonyl group, and the other is activation of the carbonyl group by coordination prior to addition of the Pd-TMM complex. 

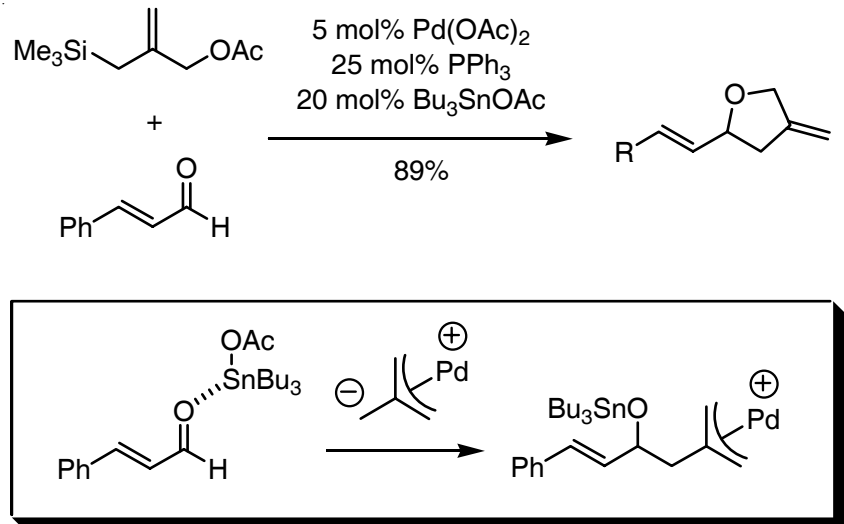

Scheme 1.67

Furukawa and co-workers [89] applied a combination of $\operatorname{PdCl}_{2}[(S)$-TolBINAP] and $\mathrm{AgBF}_{4}$ catalysts to the asymmetric 1,3-dipolar cycloaddition of nitrones to alkenes (Scheme 1.68). The desired isoxazoline was obtained in the highest yield and with high ee with $(S)$-TolBINAP as the chiral ligand. The Ag salt was added to generate a reactive cationic $\mathrm{Pd}$ complex, thereby accelerating the reaction and giving high enantioselectivity.

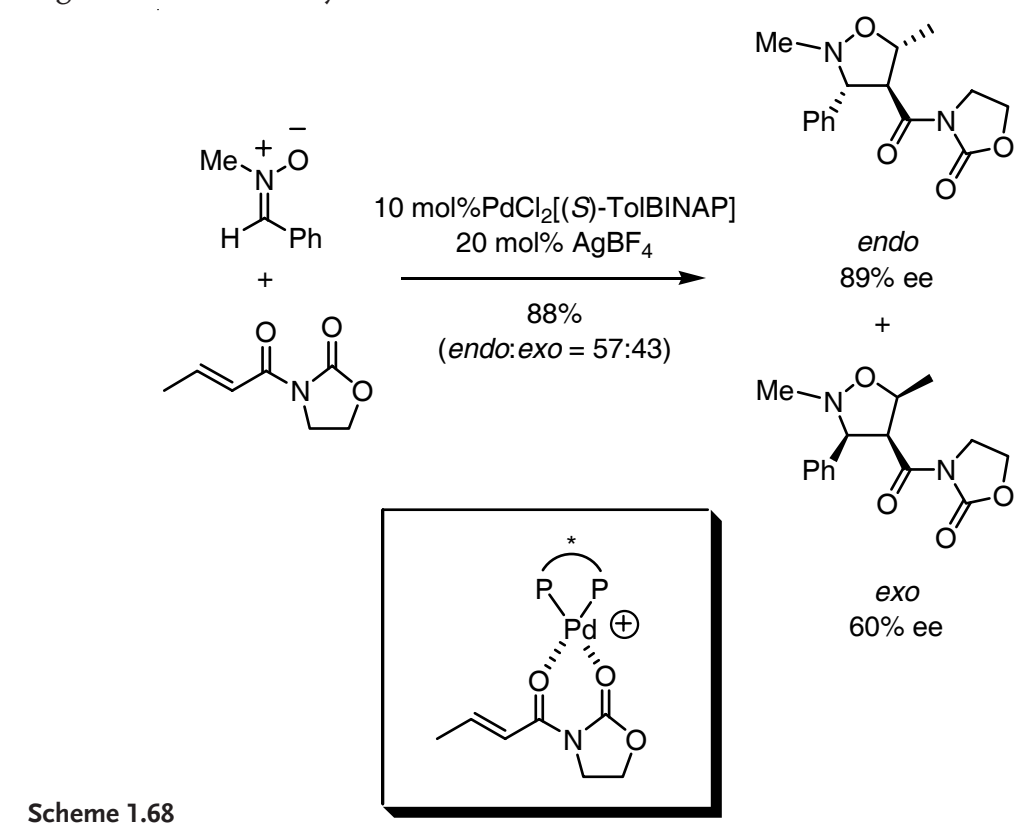

\subsubsection{Intramolecular $[\boldsymbol{n}+2]$ Cyclization Reactions}

Wender and co-workers [90] investigated the reaction of vinylcyclopropanes with a variety of $\mathrm{C}-\mathrm{C} \pi$-systems in the presence of transition metals, and they were the 
first to achieve intramolecular cycloaddition of alkynyl-vinylcyclopropanes to provide seven-membered rings based on a [5+2] cycloaddition reaction (Scheme 1.69). Essentially, the reaction could be catalyzed by $\mathrm{RhCl}\left(\mathrm{PPh}_{3}\right)_{3}$ alone, but the addition of AgOTf had a marked accelerating effect. The role of the Ag additive is assumed to be the removal of the chloride ligand from the complex, thereby freeing a coordination site and forming a more reactive cationic $\mathrm{Rh}$ center. Similar [5+2] cycloaddition reactions have been accomplished by employing alkenyl-vinylcyclopropanes [91] and allenyl-vinylcyclopropanes [92] as starting materials. Trost et al. [93] also reported that [5+2] cycloaddition reactions of alkynyl-vinylcyclopropanes proceeded under catalysis by a combination of $\left[\mathrm{CpRu}(\mathrm{MeCN})_{3}\right] \mathrm{PF}_{6}$ and $\operatorname{In}(\mathrm{OTf})_{3}$ and discussed a detailed analysis of the regioselectivity of the cyclization.

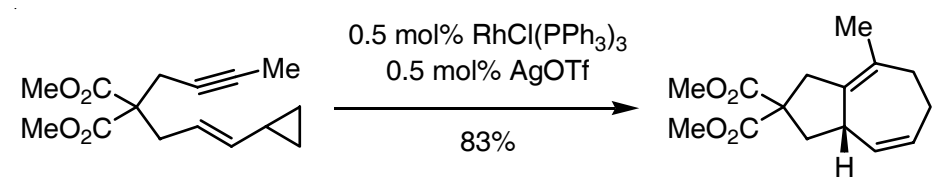

Scheme 1.69

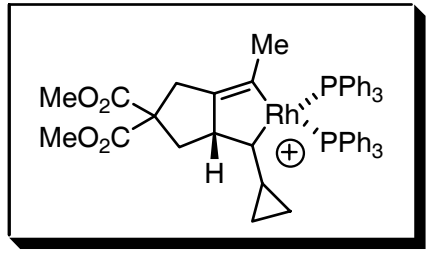

Wender and co-workers [94] also successfully accomplished a transition metal catalyzed intramolecular [6+2] cycloaddition through a reaction of 2-vinylcyclobutanone and alkene moieties (Scheme 1.70). The addition of AgOTf was not a prerequisite for the reaction to proceed when $\left[\mathrm{Rh}(\mathrm{CO})_{2} \mathrm{Cl}\right]_{2}$ was used as catalyst, but the use of the Rh-Ag bimetallic catalyst did facilitate the cycloaddition. When the reaction was conducted with $\mathrm{RhCl}(\mathrm{PPh})_{3}$ as catalyst, the addition of AgOTf was essential to obtain the desired cycloaddition products in high yields.

Scheme 1.70

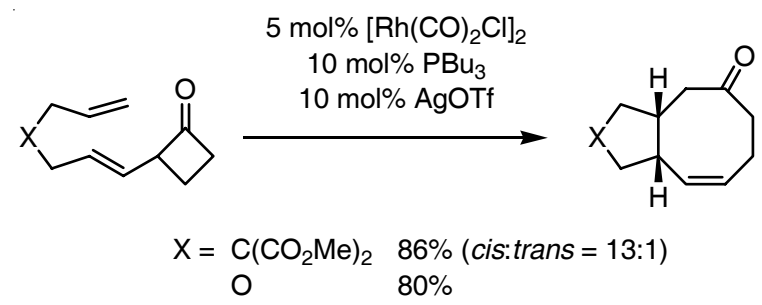

The rhodium-catalyzed intramolecular [4+2] cycloaddition reaction between dienes and alkynes was developed by Zhang and co-workers [95] (Scheme 1.71). They applied a combination of $[\mathrm{Rh}(\mathrm{dppb}) \mathrm{Cl}]_{2}$ and $\mathrm{AgSbF}_{6}$ as a catalyst system. 

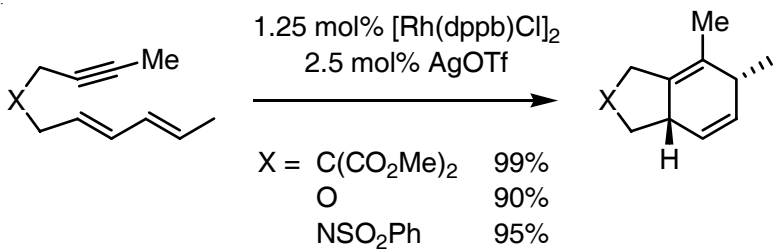

Gilbertson et al. [96] achieved the formation of eight-membered rings through a rhodium-catalyzed $[4+2+2]$ cycloaddition between alkynyl-dienes and external alkynes (Scheme 1.72). The employment of a bimetallic catalyst system, $[\mathrm{Rh}(\mathrm{NBD}) \mathrm{Cl}]_{2} / \mathrm{Me}-\mathrm{DuPHOS}$ and $\mathrm{AgSbF}_{6}$, was essential for the $[4+2+2]$ cyclization. Although the products were obtained with high diastereoselectivity, the enantioselectivity was only moderate. With other combinations of catalysts, for example $[\mathrm{Rh}(\mathrm{NBD}) \mathrm{Cl}]_{2}$ with $\mathrm{AgSbF}_{6}$ and $\left[\mathrm{Rh}(\mathrm{CO})_{2} \mathrm{Cl}_{2} / \mathrm{PPh}_{3}\right.$, only the intramolecular [4+2] cycloaddition of alkynyl-dienes took place to afford a six-membered ring.

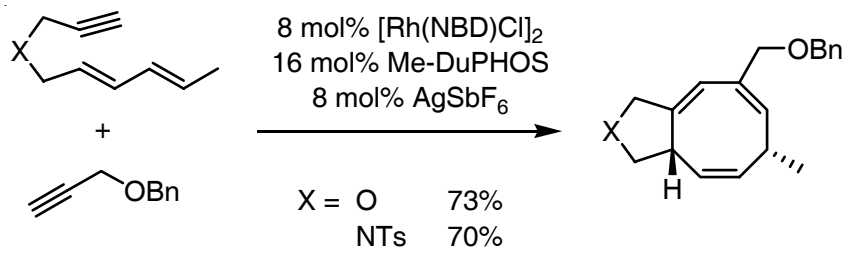

\section{Scheme 1.7}<smiles>CC1CC[C@@H](C)P1c1ccccc1P1[C@H](C)CC[C@H]1C</smiles>

$(S, S)$-Me-DuPHOS

Evans and co-workers [97] observed a similar type of [4+2+2] cycloaddition reaction between enynes and dienes under catalysis by a $\mathrm{RhCl}\left(\mathrm{PPh}_{3}\right)_{3}$ and AgOTf bimetallic system (Scheme 1.73). The choice of the Ag additive was crucial to obtain the desired product. For example, if $\mathrm{AgSbF}_{6}$ was used with the Rh catalyst, dimerization of the starting enyne to produce the tricyclic product was the predominant reaction. These authors further developed the reaction to a three-component coupling of propargylamine, allyl methyl carbonate, and a diene, in which the rhodium-catalyzed allylic amination and [4+2+2] cycloaddition occurred successively (Scheme 1.74).

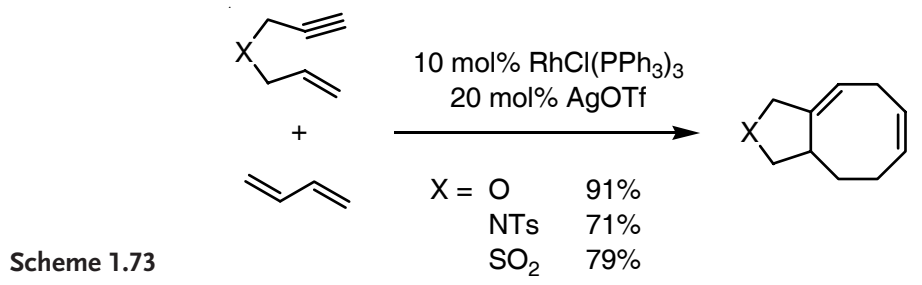




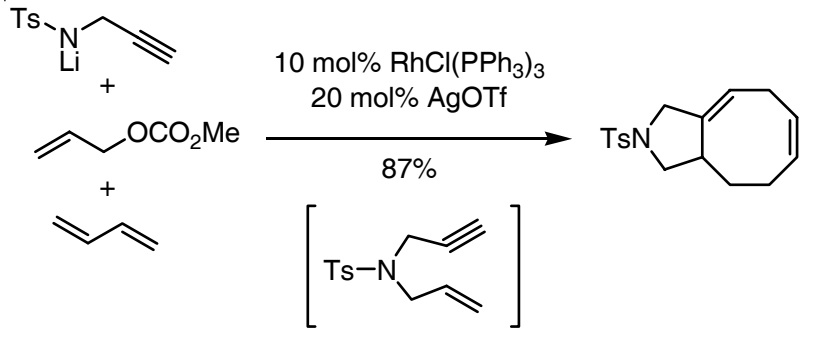

Scheme 1.74

\subsubsection{Intermolecular $[\boldsymbol{n}+2+2]$ Cyclotrimerization Reactions}

Ikeda and co-workers [98] reported the regioselective formation of substituted benzenes through the $[2+2+2]$ cyclotrimerization of $\alpha, \beta$-enones with alkynes followed by aerobic oxidation of the intermediate in the presence of DBU (Scheme 1.75). A combination of $\mathrm{Ni}(\mathrm{acac})_{2} / \mathrm{PPh}_{3}$ and $\mathrm{Me}_{3} \mathrm{Al}$ catalysts proved effective for this transformation. The Al catalyst is proposed to function as a Lewis acid and activates enones so that they form a nickelacycle intermediate. The $\mathrm{Al}$ additive may also serve to generate a reactive $\mathrm{Ni}^{0}$ catalyst in the initial stage of the catalytic cycle.
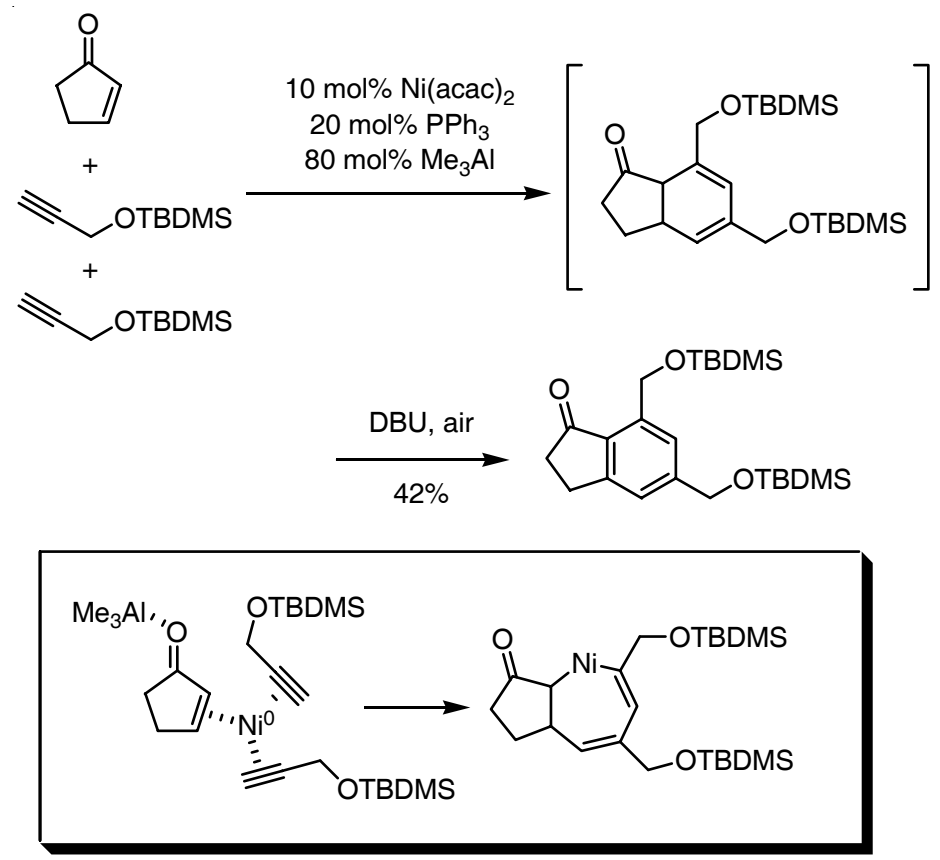

Scheme 1.75

Lyons and co-workers [99] originally devised a $[2+2+2]$ cycloaddition reaction between norbornadiene and various acetylenes in the presence of $\mathrm{Co}(\mathrm{acac})_{3} / \mathrm{dppe}$ and $\mathrm{Et}_{2} \mathrm{AlCl}$ catalysts. Later, Lautens et al. [100] carried out extensive investigations on this reaction (Scheme 1.76). It was suggested that the role of the $\mathrm{Al}$ additive is to 


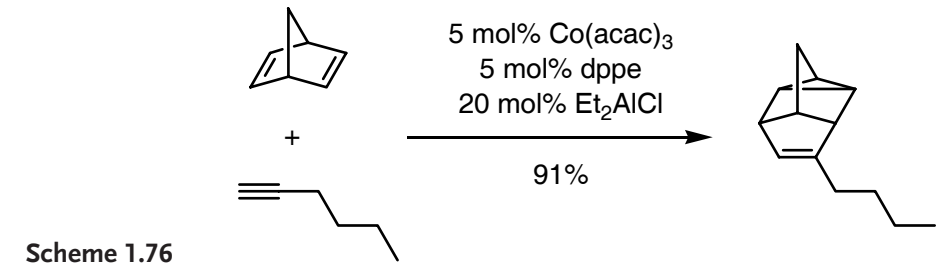

reduce the Co complex in the presence of the phosphine ligand. The asymmetric cycloaddition was explored by utilizing chiral bidentate phosphine ligands such as Chiraphos and Prophos [101]. Similar reactions have been reported by other research groups using $\mathrm{CoI}_{2} / \mathrm{PPh}_{3}$ and $\mathrm{Zn}$ powder as a catalyst system [102]. In this case, the $\mathrm{Zn}$ powder serves as a reductant for the Co pre-catalyst. When dienes were employed instead of acetylenes, a $[4+2+2]$ cycloaddition reaction took place to afford a polycyclic compound (Scheme 1.77) [103].

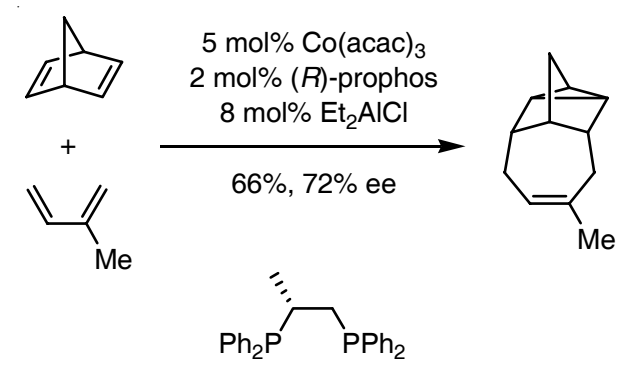

Scheme 1.77

(R)-prophos

\subsubsection{4 [2+2+1] Cycloaddition Reactions; The Pauson-Khand Reaction}

Jeong and co-workers [104] developed a one-pot preparation of bicyclopentenones from propargyl malonates or propargyl sulfonamides and allylic acetate in the presence of $\mathrm{Pd}_{2}(\mathrm{dba})_{3} \cdot \mathrm{CHCl}_{3} / \mathrm{dppp}$ and $[\mathrm{RhCl}(\mathrm{CO})(\mathrm{dppp})]_{2}$ as a heterobimetallic catalyst system (Scheme 1.78). The overall transformation consists of two con-

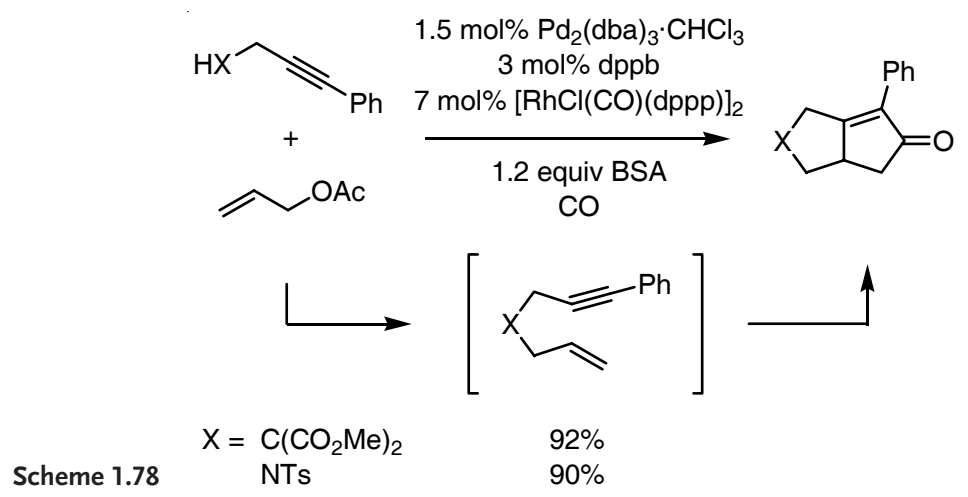


secutive reactions. The first reaction is the palladium-catalyzed formation of enynes through allylic substitution, and the second one is the rhodium-catalyzed PausonKhand reaction to construct the cyclopentenone framework.

\subsubsection{Cycloisomerization Reactions}

Zhang et al. [105] reported the transition metal catalyzed cycloisomerization of 1,6-enynes, which led to the formation of cyclic compounds incorporating a 1,4-diene moiety (Scheme 1.79). The catalyst was prepared in situ from $[\mathrm{RhCl}(\mathrm{dppb})]_{2}$ and $\mathrm{AgSbF}_{6}$. The role of the $\mathrm{Ag}$ additive was to generate an active cationic $\mathrm{Rh}$ species. Enantioselective rhodium-catalyzed cycloisomerization was also studied by utilizing chiral bidentate phosphine ligands [106]. A similar cycloisomerization using a combination of $\mathrm{NiCl}_{2}\left(\mathrm{PPh}_{3}\right)_{2}$ and $\mathrm{CrCl}_{2}$ catalysts was reported by Trost et al. [107] (Scheme 1.80).

Scheme 1.79
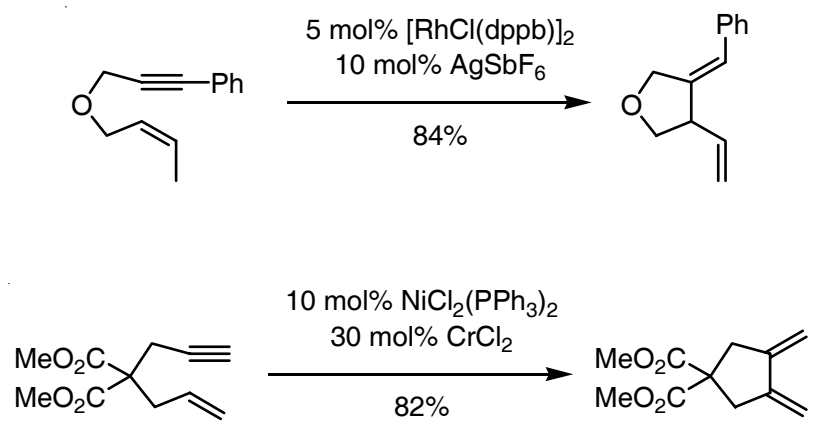

Scheme 1.80

\subsubsection{Indole-Forming Reaction}

We developed a synthesis of 3-allyl- $\mathrm{N}$-(alkoxycarbonyl)indoles from isocyanates and allyl carbonate using a combined catalyst system comprising $\mathrm{Pd}\left(\mathrm{PPh}_{3}\right)_{4}$ and $\mathrm{CuCl}$ (Scheme 1.81) [108]. The Pd catalyst is a precursor of a $\pi$-allylpalladium methoxide, generated through the reaction with allyl methyl carbonate. The $\mathrm{Cu}$ catalyst is proposed to serve a dual role, activating the isocyanate functional group as a Lewis acid so as to facilitate the addition of the $\pi$-allylpalladium methoxide, and simultaneously coordinating to the alkyne moiety as a typical transition metal catalyst to promote the ensuing cyclization to construct the indole core.

Watanabe and co-workers [109] reported an indole synthesis involving reductive $N$-heterocyclization of nitroarenes using $\mathrm{PdCl}_{2}\left(\mathrm{PPh}_{3}\right)_{2}$ and $\mathrm{SnCl}_{2}$ catalysts under a $\mathrm{CO}$ atmosphere (Scheme 1.82). The reaction required both $\mathrm{Pd}$ and Sn catalysts, although their roles in the catalytic cycle were obscure. The carbon monoxide (CO) operates as an efficient deoxygenating agent for 2-nitrostyrenes and extrusion of $\mathrm{CO}_{2}$ generates the corresponding palladium-nitrene intermediates. The $\mathrm{Sn}$ catalyst might be involved in the reduction process of the nitro group. The electrophilic nitrene probably attacks the olefinic carbon, and subsequent hydrogen transfer via $[1,5]$-sigmatropic rearrangement gives the indole core. 


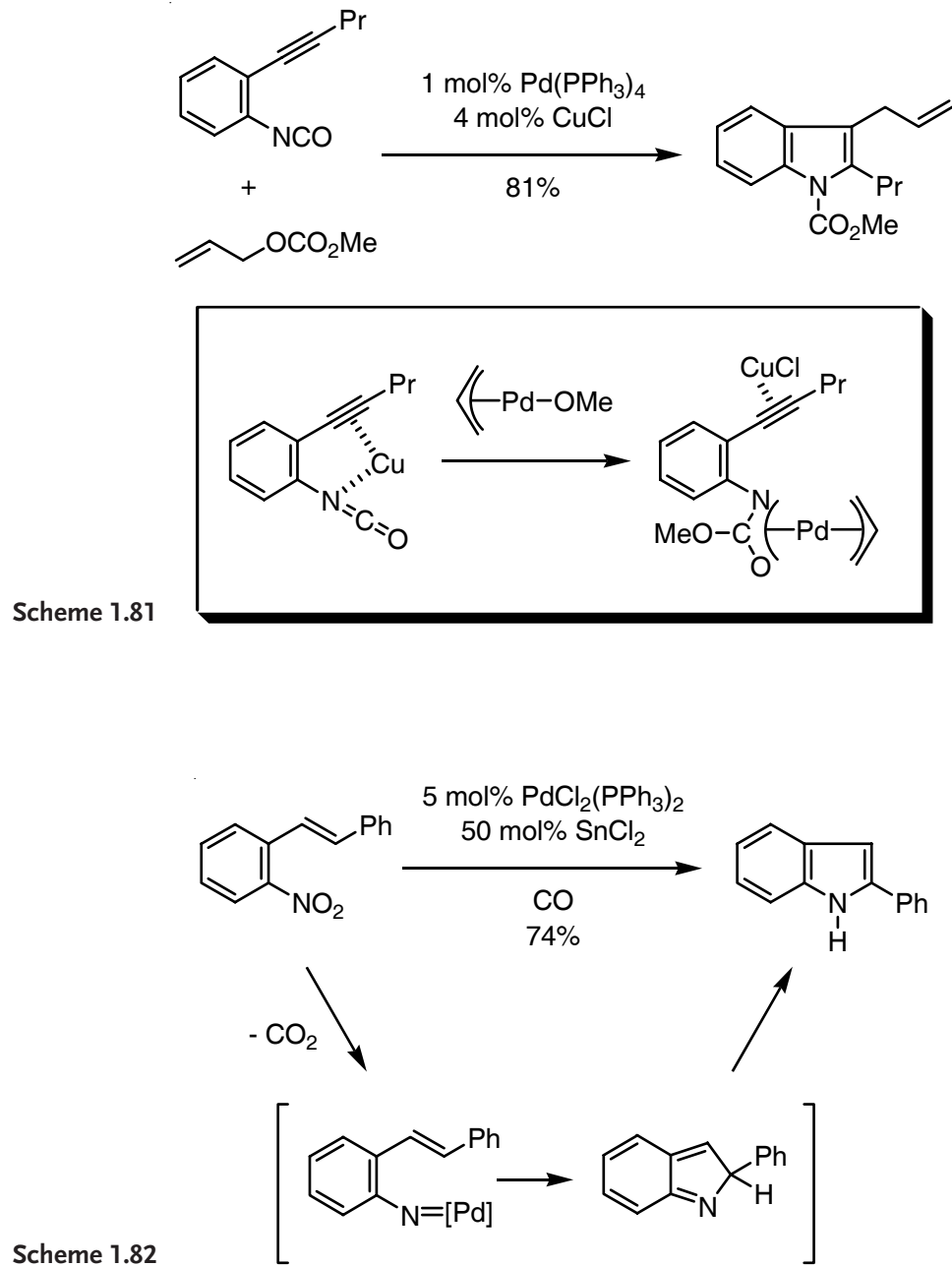

\subsubsection{Furan- and Pyrrole-Forming Reactions}

Hidai and Uemura et al. [110] disclosed a heterobimetallic-catalyzed synthesis of furans from propargyl alcohols and ketones (Scheme 1.83). This reaction could only be realized with a combination of a thiolate-bridged diruthenium complex, $\left[\mathrm{Cp} * \mathrm{RuCl}(\mu-\mathrm{SMe})_{2} \mathrm{RuCp} * \mathrm{Cl}\right]$, and $\mathrm{PtCl}_{2}$. The overall process consists of two consecutive reactions. Substitution with acetone at the propargyl position most probably takes place in the presence of the Ru complex to afford the corresponding $\gamma$-ketoalkyne intermediate. Then, Pt-catalyzed hydration of the alkyne with $\mathrm{H}_{2} \mathrm{O}$ generated in situ produces the 1,4-diketone, which undergoes intramolecular cyclization catalyzed by the Pt complex to afford the furan derivative. When the above reaction was carried out in the presence of anilines, the corresponding pyrroles were obtained through imine intermediates (Scheme 1.84). 


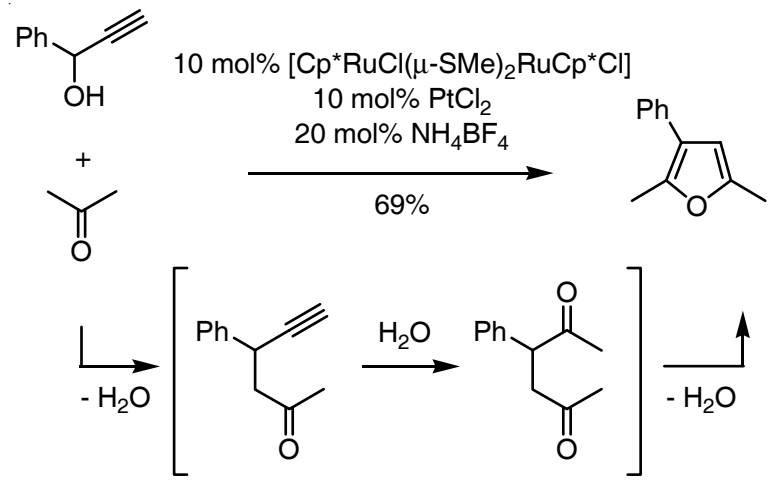

Scheme 1.83
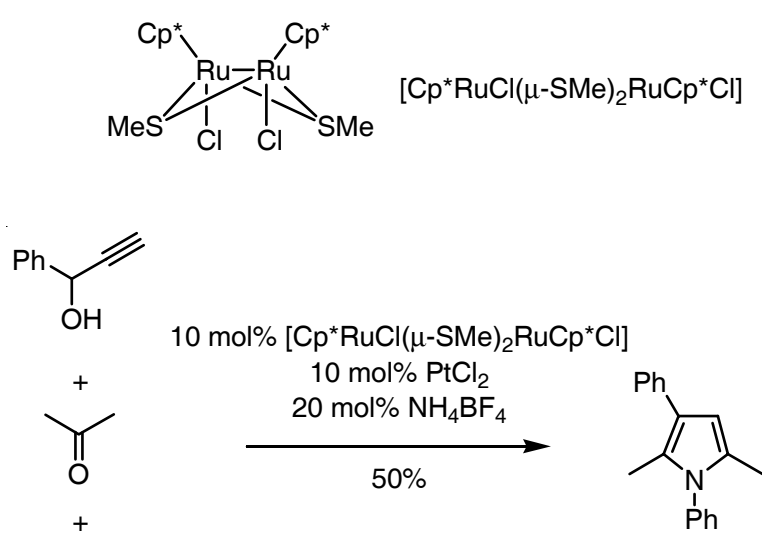

10 mol\% $\left[\mathrm{Cp}{ }^{*} \mathrm{RuCl}(\mu-\mathrm{SMe})_{2} \mathrm{RuCp}{ }^{\star} \mathrm{Cl}\right]$

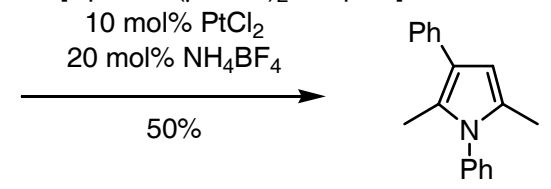

Scheme 1.84

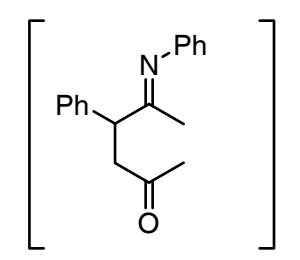

135

Reactions Involving Nucleophilic Addition of Carbonyl Compounds

\subsubsection{The Aldol Reaction}

Shibasaki and Sodeoka et al. [111] investigated a catalytic asymmetric aldol reaction involving a chiral $\mathrm{Pd}^{\mathrm{II}}$ enolate (Scheme 1.85). The highest enantioselectivity was observed when the reaction was conducted in the presence of a combination of $\mathrm{PdCl}_{2}[(R)$-BINAP] and AgOTf catalysts in wet DMF. The Ag catalyst abstracts a chloride ion from the $\mathrm{Pd}$ center to generate a reactive cationic Pd species. Transmetalation between the Pd catalyst and a silyl enol ether forms the chiral Pd ${ }^{\mathrm{II}}$ enolate, which controls the orientation of a prochiral enolate during the course of the reaction with the aldehyde. 


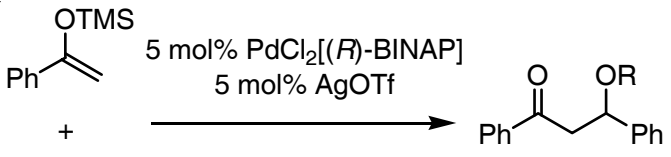

$\mathrm{PhCHO} \quad \mathrm{R}=\mathrm{TMS} \quad 87 \%, 71 \%$ ee

$\mathrm{R}=\mathrm{H} \quad 9 \%, 73 \%$ ee

Scheme 1.85

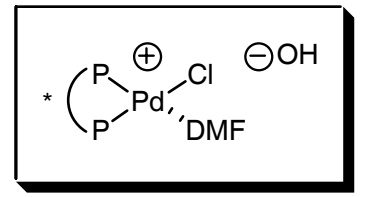

\subsubsection{Alkynylation Reactions}

Li et al. [112] studied the alkynylation of aldehydes through a Grignard-type reaction involving $\mathrm{C}-\mathrm{H}$ bond activation (Scheme 1.86). The corresponding alkynylated products were obtained from the reaction of terminal alkynes with aldehydes in the presence of $\mathrm{RuCl}_{3}$ and $\mathrm{In}(\mathrm{OAc})_{3}$ as a bimetallic catalyst system. The addition of morpholine increased the conversion of the reaction. The key to this transformation is that the In salt functions as a Lewis acid to activate the starting aldehydes even in the presence of water. The Ru catalyst simultaneously inserts into the $\mathrm{C}-\mathrm{H}$ bond of the alkyne and the derived Ru-acetylide intermediate undergoes Grignard-type addition to the aldehyde activated by coordination of the In salt. When imines were used as reaction partners, a combination of $\mathrm{RuCl}_{3}$ and $\mathrm{CuBr}$ catalysts proved effective for successful reaction (Scheme 1.87) [113]. Without the addition of the $\mathrm{Cu}$ salt, no reaction took place. Activation of an imine through coordination of the $\mathrm{Cu}$ additive is essential for addition of the Ru-acetylide species.

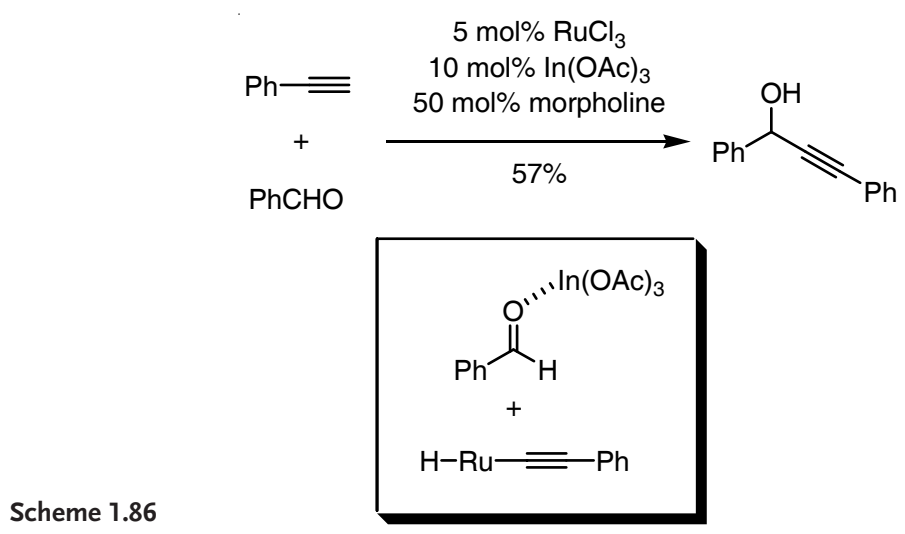




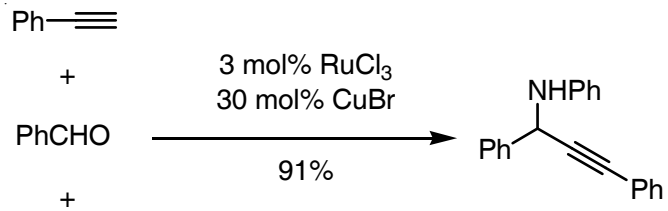

Scheme 1.87

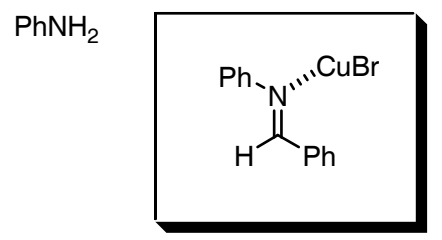

\subsubsection{Conjugate Addition Reactions}

Trost and co-workers [114] reported a ruthenium-catalyzed three-component addition reaction of terminal alkynes, $\alpha, \beta$-unsaturated carbonyl compounds, and nucleophilic reactants. 1,5-Diketones were obtained using $\mathrm{H}_{2} \mathrm{O}$ as a nucleophilic agent in the presence of a combination of $\mathrm{CpRu}(\mathrm{COD}) \mathrm{Cl}$ and $\mathrm{In}(\mathrm{OTf})_{3}$ catalysts (Scheme 1.88). The reaction proceeds through attack of $\mathrm{H}_{2} \mathrm{O}$ on the alkyne, which is activated by the $\pi$-coordination of a cationic ruthenium species. The derived ruthenium-enolate, equivalent to a vinylruthenium intermediate, then adds to the $\alpha, \beta$-unsaturated ketone in a 1,4-manner. The role of the In salt remains to be clarified, although it is proposed that it prevents deactivation of the Ru catalyst by facilitating chloride dissociation and that it activates the vinyl ketones by coordination as a Lewis acid catalyst. A similar type of reaction was carried out using $\mathrm{Me}_{4} \mathrm{NCl}$ as a nucleophilic agent (Scheme 1.89) [115]. In this case, (E)-vinyl chlorides were obtained as the major products. A bimetallic catalyst comprising $\mathrm{CpRu}(\mathrm{COD}) \mathrm{Cl}$ and $\mathrm{SnCl}_{4} \cdot 5 \mathrm{H}_{2} \mathrm{O}$ was found to be the optimal catalyst system for this transformation. When $\mathrm{LiBr}$ was used as a nucleophilic agent, $(Z)$-vinyl bromides were obtained as the major products in the presence of $\left[\mathrm{CpRu}(\mathrm{MeCN})_{3}\right] \mathrm{PF}_{6}$ and $\mathrm{SnBr}_{4}$ catalysts (Scheme 1.90) [116]. The high $Z$-selectivity in forming the adducts can be

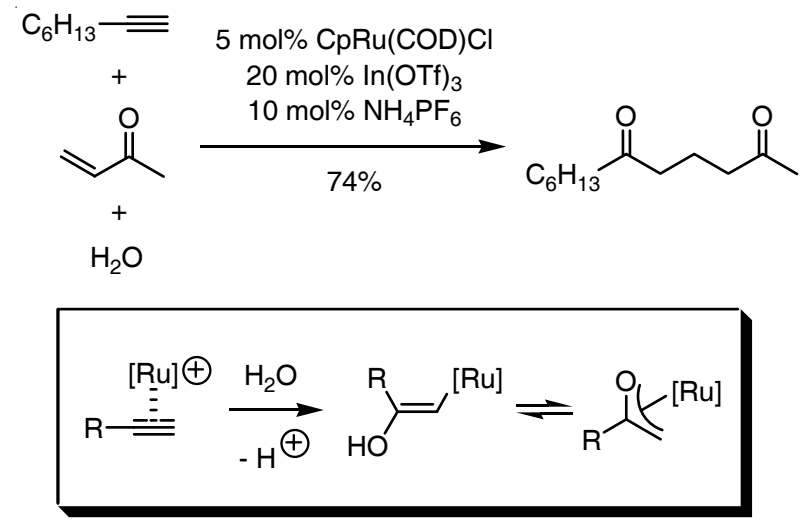

Scheme 1.88 

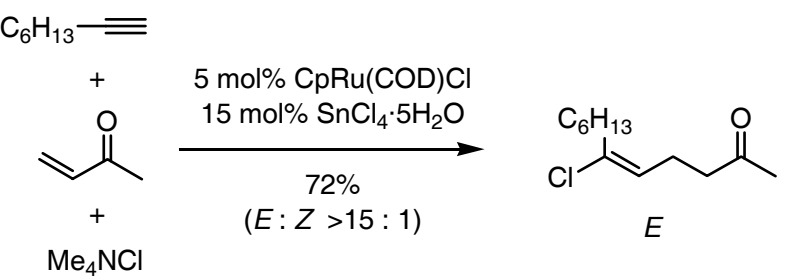

Scheme 1.89
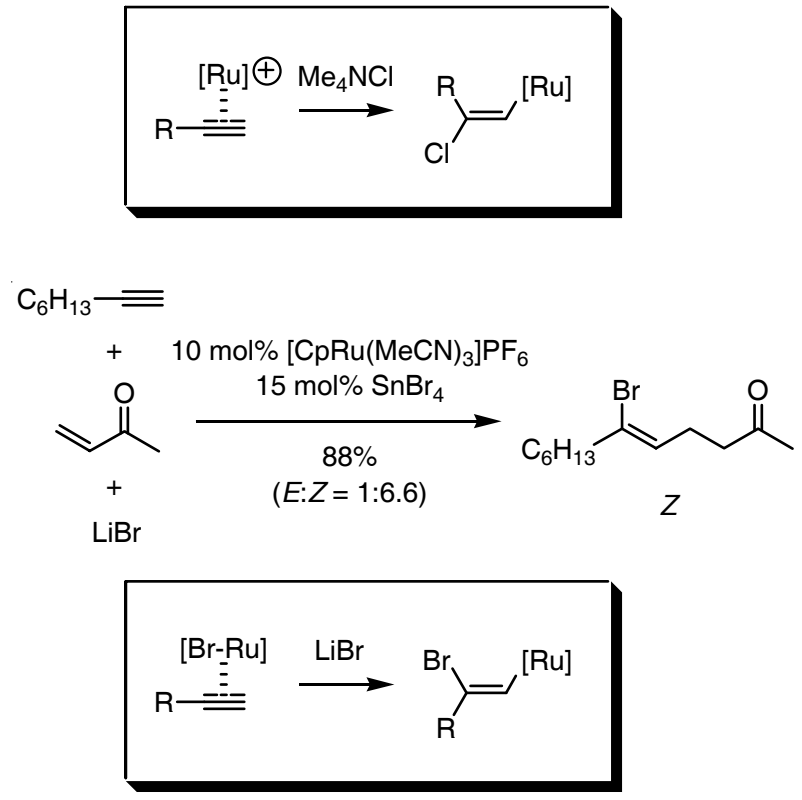

Scheme 1.90

rationalized by invoking a mechanism in which the vinylruthenium intermediate is formed by cis-addition of a neutral $\mathrm{Ru}-\mathrm{Br}$ species to the alkyne.

\subsection{6}

Miscellaneous Reactions

\subsubsection{Transition Metal Catalyzed Reactions}

Shi and co-workers [117] reported that the hydroamination of methylenecyclopropanes (MCPs) with sulfonamides was effectively catalyzed by a combination of $\mathrm{Pd}\left(\mathrm{PPh}_{3}\right)_{4}$ and $\mathrm{Pd}(\mathrm{OAc})_{2}$ catalysts (Scheme 1.91). The use of a single $\mathrm{Pd}^{0}$ catalyst, such as $\mathrm{Pd}\left(\mathrm{PPh}_{3}\right)_{4}$ or $\mathrm{Pd}_{2}(\mathrm{dba})_{3}$, or a single $\mathrm{Pd}^{\mathrm{II}}$ catalyst, such as $\mathrm{PdCl}_{2}\left(\mathrm{PPh}_{3}\right)_{2}$ or $\mathrm{Pd}(\mathrm{OAc})_{2}$, did not promote the ring-opening reaction of MCPs with toluenesulfonamide. When the reaction was carried out with the $\mathrm{Pd}^{0}-\mathrm{Pd}^{\mathrm{II}}$ combined catalyst, $\mathrm{Pd}\left(\mathrm{PPh}_{3}\right)_{4}$ and $\mathrm{Pd}(\mathrm{OAc})_{2}$, the corresponding diallyl tosylamide was obtained in excellent yield. The $\mathrm{Pd}^{0}$ catalyst serves as a precursor of a hydridepalladium amide species. The $\mathrm{Pd}^{\mathrm{II}}$ catalyst is assumed to act as a weak Lewis acid in coordinating to the double bond of MCP and accelerates the ring-opening of the cyclopropane moiety after the hydropalladation has taken place. 


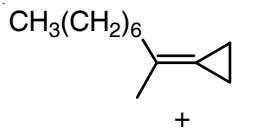

$\mathrm{TsNH}_{2}$

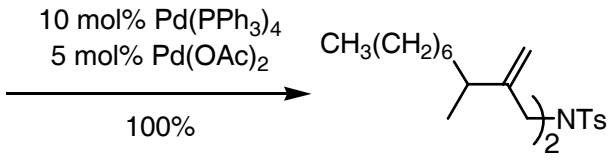

$f_{2}^{N T s}$

Scheme 1.91

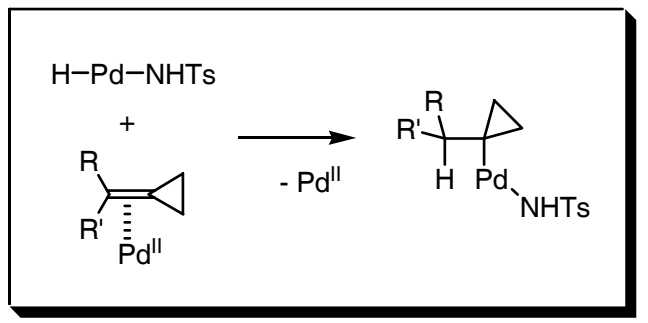

Shirakawa and co-workers [118] employed $\mathrm{Pd}(\mathrm{OAc})_{2} / \mathrm{PPh}_{3}$ and $\operatorname{In}(\mathrm{OTf})_{3}$ as a combined catalyst system for the dimerization of vinylarenes (Scheme 1.92). The reaction of styrene gave 1,3-diphenyl-1-butene selectively. The role of the In additive is probably to activate the vinylarenes by making them more susceptible to nucleophilic attack by the $\mathrm{Pd}^{0}$ complex. Then, the palladium intermediate undergoes insertion of another vinylarene to provide the dimerized product.
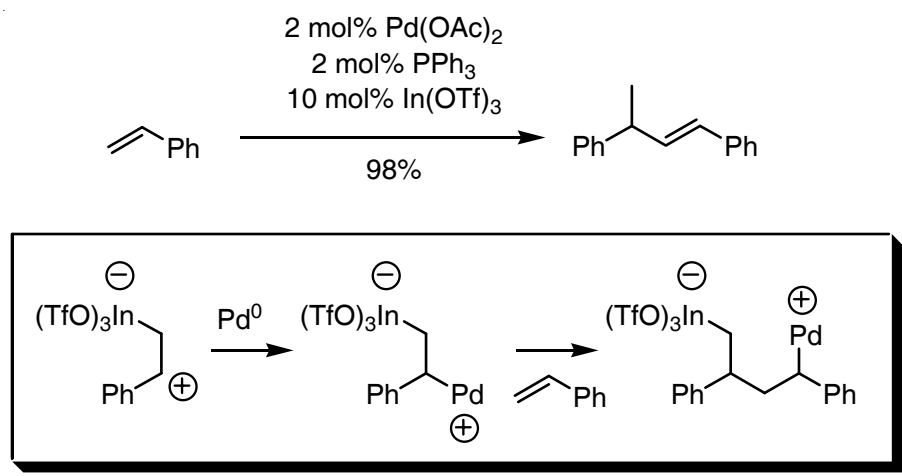

Scheme 1.92

Trost et al. [119] investigated redox isomerization of propargyl alcohols to enals and enones, and found that a combination of $\left(\eta^{5}\right.$-indenyl) $\mathrm{RuCl}\left(\mathrm{PPh}_{3}\right)_{2}$ and $\mathrm{InCl}_{3}$ catalysts effectively promoted isomerization to afford the corresponding $\alpha, \beta$ unsaturated carbonyl compounds (Scheme 1.93). The reaction proceeded to some extent in the presence of the Ru catalyst alone, albeit only to a low conversion. Two possibilities are proposed for the effect of the In additive. One is that the In catalyst functions as a chloride scavenger, thereby generating a reactive cationic Ru species. The other is the formation of an In-bridged intermediate to release the strain and to accelerate the ensuing hydride migration. 


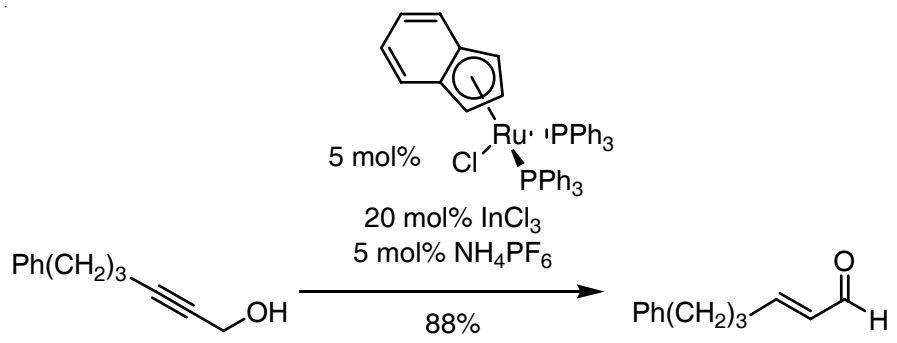

Scheme 1.93

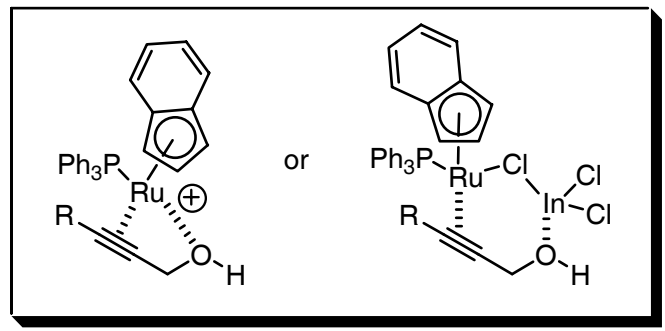

Tsukada and Inoue et al. [120] reported a stereoselective cis-addition of aromatic $\mathrm{C}-\mathrm{H}$ bonds to alkynes by using a dinuclear palladium catalyst, $\mathrm{Pd}_{2}\left(p-\mathrm{CH}_{3}-\mathrm{C}_{6} \mathrm{H}_{4}\right)_{2}(\mu-$ $\mathrm{OH})\left(\mu\right.$-dpfam) $\left(\mathrm{dpfam}=N, N^{\prime}\right.$-bis[2-(diphenylphosphino)phenyl]formamidinate) (Scheme 1.94). A mechanistic rationale was not provided, but this reaction did not take place in the presence of typical palladium complexes such as $\mathrm{Pd}(\mathrm{OAc})_{2}$ or $\mathrm{Pd}_{2}(\mathrm{dba})_{3} \cdot \mathrm{CHCl}_{3}$, nor with mononuclear PdMe(dpfam).
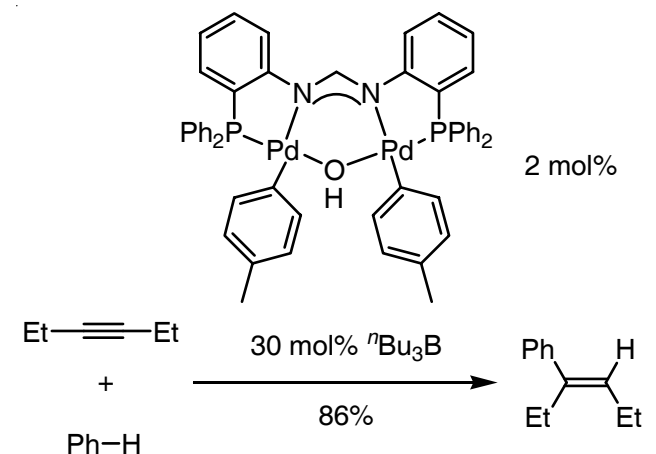

\subsubsection{Lewis Acid Catalyzed Reactions}

Maruoka and co-workers designed a homobimetallic titanium system as a bidentate Lewis acid catalyst. The simultaneous coordination of a carbonyl group in a $\sigma, \sigma$-complexation mode with a bidentate Lewis acid enhances the reactivity and selectivity of the carbonyl substrate compared to coordination by a corresponding monodentate Lewis acid. The allylation of benzaldehyde with tetraallyltin is a typical example where such reactivity enhancement is observed (Scheme 1.95) [121]. 
1.3 Reactions Promoted by a Combination of Catalytic Amounts of Two Metals $\mid 45$

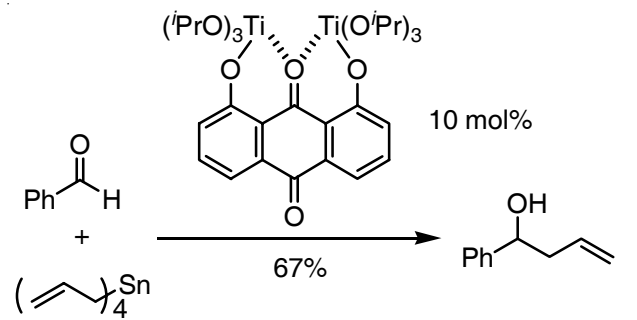

Scheme 1.95
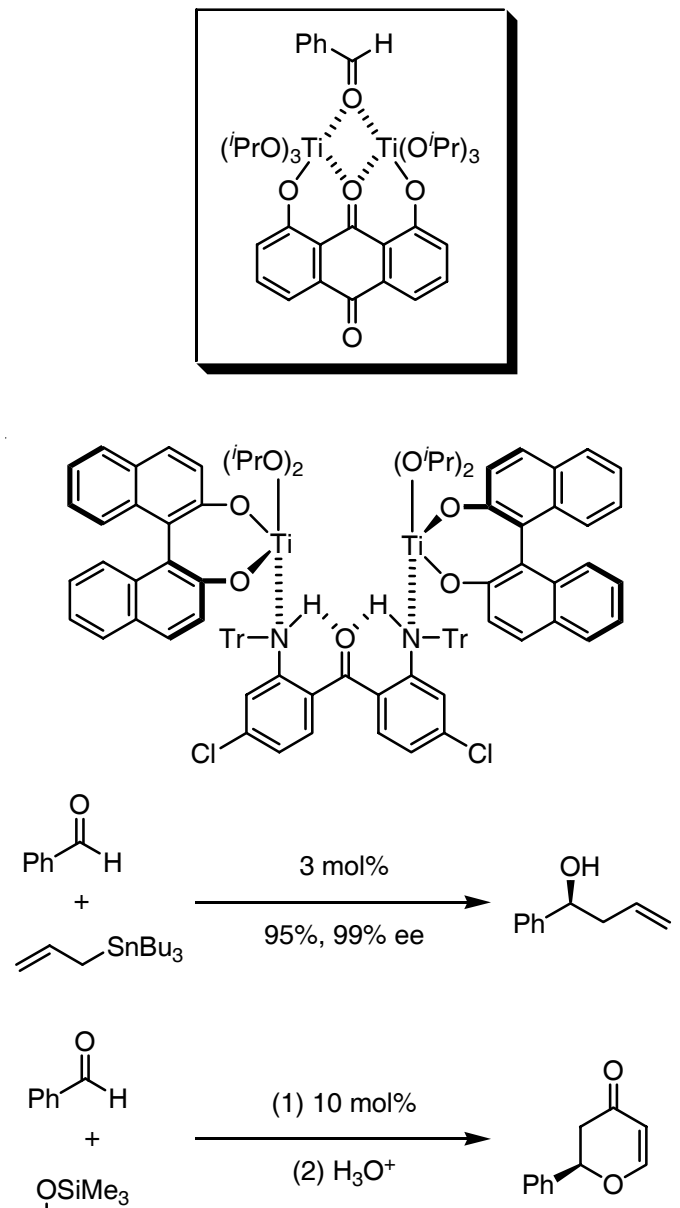

$\mathrm{C}_{\mathrm{OMe}} 64 \%, 71 \%$ ee

Scheme 1.96

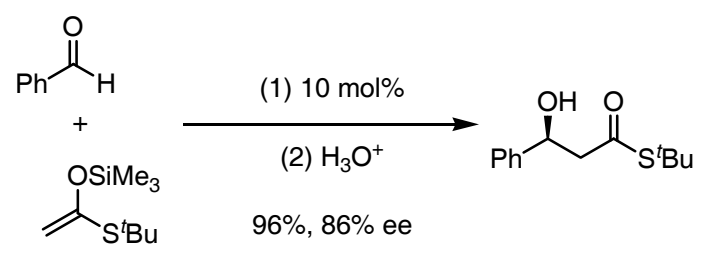


Use of the bis-Ti complex led to the corresponding adduct in good yield, whereas the use of the mono-Ti complex gave only a trace amount of the product. Further developments have involved the use of bis-Ti complexes bearing binaphthol ligands, and these systems have enabled asymmetric allylations [122], enantioselective heteroDiels-Alder reactions, and aldol reactions of aldehydes (Scheme 1.96) [123].

\subsubsection{Sequential Reactions}

Doye and co-workers [124] developed a one-pot procedure for the synthesis of indoles through two sequential reactions, namely the hydroamination of alkynes and an aromatic amination reaction, without isolating the intermediates (Scheme 1.97). The Ti complex $\mathrm{Cp}_{2} \mathrm{TiMe}_{2}$ was found to promote the hydroamination of alkynes to produce imine intermediates, and the $\mathrm{Pd}$ complex $\mathrm{Pd}_{2}(\mathrm{dba})_{3}$, in combination with an imidazolium ligand, catalyzed the intramolecular aromatic amination reaction of the corresponding enamine under basic conditions to form the indole skeleton.

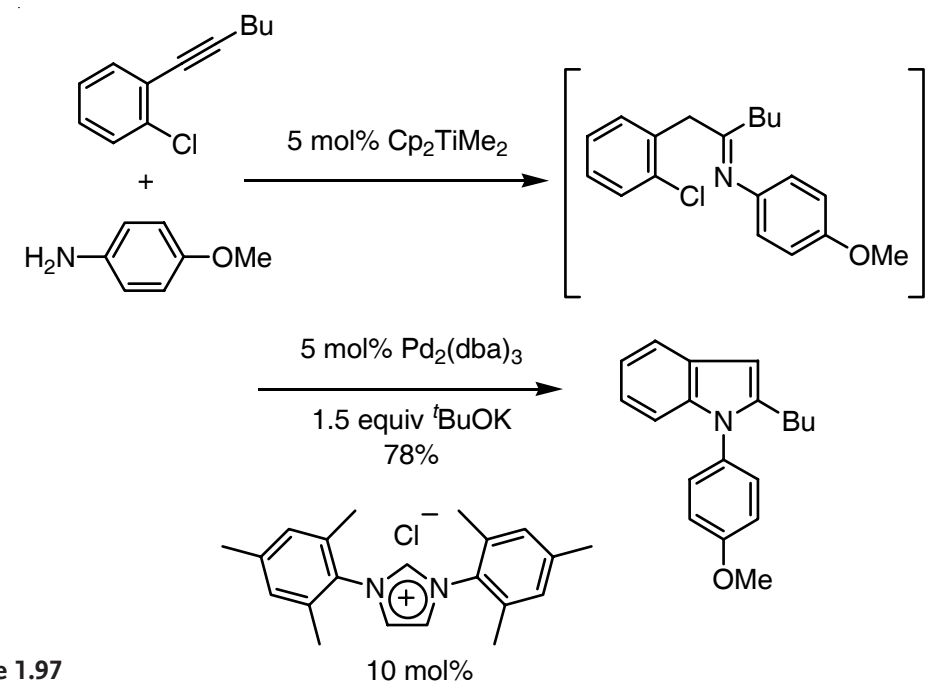

Trost et al. [125] reported a one-pot enantio- and diastereoselective synthesis of heterocycles using ruthenium and palladium catalysts (Scheme 1.98). The Ru complex $\left[\mathrm{CpRu}(\mathrm{MeCN})_{3}\right] \mathrm{PF}_{6}$ was found to catalyze the coupling between the starting alkyne and alkene to form the diene intermediate bearing suitable functional groups in the appropriate positions for the second step. After the formation of the diene intermediate, the Pd complex $\mathrm{Pd}_{2}(\mathrm{dba})_{3} \cdot \mathrm{CHCl}_{3}$, together with the chiral bidentate phosphine ligand, was added to the reaction mixture to promote the asymmetric allylic alkylation. An enantioselective cyclization took place to afford pyrrolidine derivatives. These authors succeeded in obtaining not only N-containing but also O-containing cyclic compounds in good yields and with high enantioselectivities.

Hayashi and co-workers [126] successfully accomplished an asymmetric synthesis of 1-aryl-1,2-ethanediols from arylacetylenes through stepwise hydrosilylation of 


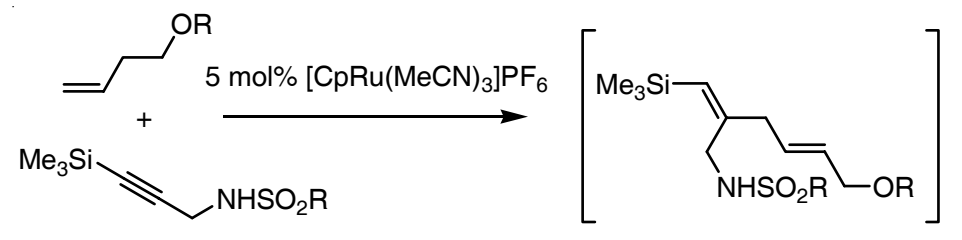

$\mathrm{R}=p-\mathrm{NO}_{2}-\mathrm{C}_{6} \mathrm{H}_{4}$
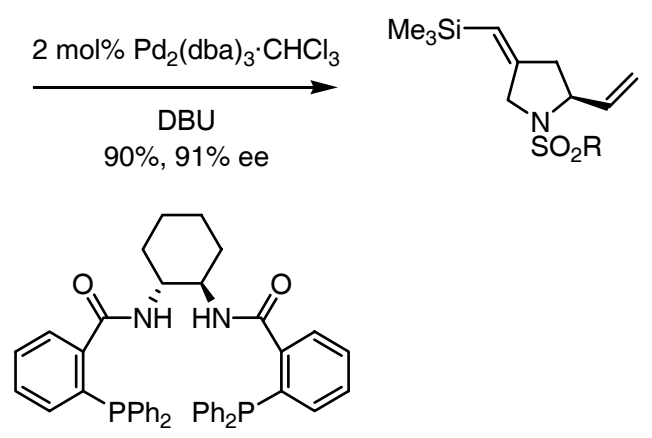

Scheme 1.98

$6 \mathrm{~mol} \%$

the alkynes using platinum and palladium catalysts (Scheme 1.99). The Pt catalyst, $\left[\mathrm{PtCl}_{2}\left(\mathrm{C}_{2} \mathrm{H}_{4}\right)\right]_{2}$, promoted hydrosilylation of the alkyne to afford the vinylsilane intermediate in a regioselective manner, while the Pd catalyst, $\left[\left(\eta^{3}-\mathrm{C}_{3} \mathrm{H}_{5}\right) \mathrm{PdCl}\right]_{2}$, together with the chiral phosphine ligand, promoted asymmetric hydrosilylation of the derived vinylsilane to afford the 1,2-bis(silyl)ethane derivative. Subsequent oxidation using hydrogen peroxide produced the corresponding diol as the final product with high enantioselectivity.

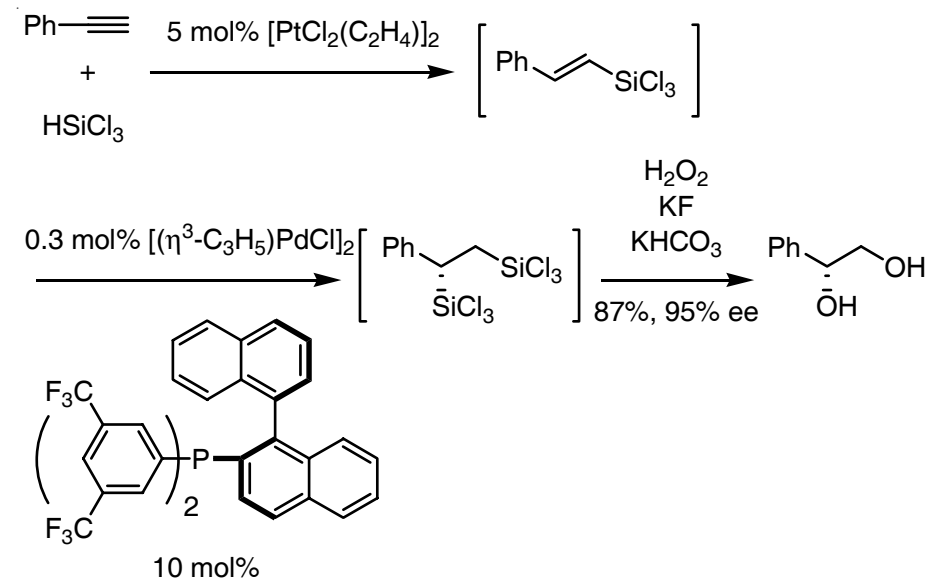

Scheme 1.99 


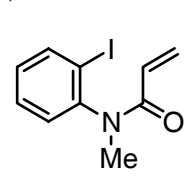

$10 \mathrm{~mol} \% \mathrm{Pd}(\mathrm{OAc})_{2}$

$20 \mathrm{~mol} \% \mathrm{PPh}_{3}$

1 equiv $\mathrm{K}_{2} \mathrm{CO}_{3}$<smiles>C=C1C(=O)N(C)c2ccccc21</smiles><smiles>COC(=O)C(Cc1ccccc1)N=Cc1ccccc1</smiles><smiles>COC(=O)C1(Cc2ccccc2)C[C@@]2(C(=O)N(C)c3ccccc32)[C@H](c2ccccc2)N1</smiles>

Scheme 1.100<smiles></smiles>

Grigg and co-workers [127] investigated the synthesis of spiro-oxindoles by a sequence of intramolecular Heck reaction followed by 1,3-dipolar cycloaddition using palladium and silver catalysts (Scheme 1.100). The Pd complex, $\mathrm{Pd}(\mathrm{OAc})_{2} /$ $\mathrm{PPh}_{3}$, promotes the intramolecular Heck reaction to afford a relatively unstable 3-methyleneoxindole intermediate. The introduction of the $\mathrm{Ag}$ salt, $\mathrm{Ag}_{2} \mathrm{O}$, together with the imine and DBU, provides the corresponding azomethine ylide, which undergoes [3+2] cycloaddition with the methyleneoxindole intermediate to furnish the spiro-oxindole regiospecifically.

\section{References}

1 N. Krause (Ed.), Modern Organocopper Chemistry, Wiley-VCH, Weinheim, 2002; (b) R. J. K. TAYlor (Ed.), Organocopper Reagents, Oxford University Press, Oxford, 1994.

2 (a) F. Diederich, P. J. StAng (Eds.), Metal-Catalyzed Cross-Coupling Reactions, Wiley-VCH, Weinheim, 1998; (b) J. Tsuj, Transition Metal Reagents and Catalysts, Wiley, Chichester, 2000.

3 (a) S. Gronowitz, A. Messmer, G. Timári, J. Heterocycl. Chem. 1992, 29, 1049; (b) S. Gronowitz, P. BJöRK, J. Malm, A.-B. Hörnfeldt, J. Organomet. Chem. 1993, 460, 127.
4 M. Kosugi, Y. Negishi, M. Kameyama, T. Migita, Bull. Chem. Soc. Jpn. 1985, 58, 3383.

5 X. Han, B. M. Stoltz, E. J. Corey, J. Am. Chem. Soc. 1999, 121, 7600.

6 R. Wittenberg, J. Srogl, M. Egi, L. S. Liebeskind, Org. Lett. 2003, 5, 3033.

7 M. Egi, L. S. Liebeskind, Org. Lett. 2003, 5, 801.

8 F.-A. Alphonse, F. Suzenet, A. Keromnes, B. Lebret,

G. Guillaumet, Org. Lett. 2003, 5, 803.

9 (a) M. Kosugi, I. Hagiwara, T. Sumiyama, T. Migita, J. Chem. Soc., Chem. Commun. 1983, 344; 
(b) M. Kosugi, I. Hagiwara, T. Migita, Chem. Lett. 1983, 839; (c) M. KosugI, I. Hagiwara, T. Sugiyama, T. Migita, Bull. Chem. Soc. Jpn. 1984, 57, 242.

10 I. Kuwajima, H. Urabe, J. Am. Chem. Soc. 1982, 104, 6831.

11 (a) K. Hirabayashi, J. Kawashima, Y. Nishinara, A. Mori, T. Hiyama, Org. Lett. 1999, 1, 299; (b) K. Hirabayashi, A. Mori, J. Kawashima, M. Suguro, Y. Nishinara, T. Hiyama, J. Org. Chem. 2000, 65, 5342.

12 S. Chang, S. H. Yang, P. H. Lee, Tetrahedron Lett. 2001, 42, 4833.

13 (a) L. S. Hegedus, Comprehensive Organic Synthesis, Vol. 4 (Ed.: B. M. TRost, I. Fleming), Pergamon, Oxford, 1991, p. 551; (b) J. Tsuji, Synthesis 1984, 369.

14 T. Hosokawa, M. Hirata, S. MuraHASHI, A. SONODA, Tetrahedron Lett. 1976, 21, 1821.

15 A. I. Roshchin, S. M. Kel'chevski, N. A. Bumagin, J. Organomet. Chem. 1998, 560, 163.

16 (a) M. F. Semmelhack, C. Bodurow, J. Am. Chem. Soc. 1984, 106, 1496; (b) M. F. Semmelhack, C. Кim, N. Zhang, C. Bodurow, M. Sanner, W. Doubler, M. Meier, Pure Appl. Chem. 1990, 62, 2035

17 Y. Tamaru, T. Kobayashi, S. Kawamura, H. Ochiai, M. Нojo, Z. Yoshida, Tetrahedron Lett. 1985, 26, 3207.

18 M. F. Semmelhack, W. R. Epa, Tetrahedron Lett. 1993, 34, 7205.

19 (a) D. Lathbury, P. Vernon, T. Gallagher, Tetrahedron Lett. 1986, 27, 6009; (b) D. N. A. Fox, T. Gallagher, Tetrahedron 1990, 46, 4697;

(c) T. Gallagher, I. W. Davies, S. W. Jones, D. Lathbury, M. F. Mahon, K. C. Molloy, R. W. Shaw, P. Vernon, J. Chem. Soc., Perkin Trans. 1 1992, 433.

20 (a) M. Kimura, N. Saeki, S. Uchida, H. Harayama, S. Tanaka, K. Fugami, Y. TAMARU, Tetrahedron Lett. 1993, 34, 7611; (b) Y. Tamaru, M. Kimura, Synlett 1997, 749.

21 Y. TAmaru, M. Hojo, Z. Yoshida, J. Org. Chem. 1988, 53, 5731.

22 (a) T. Pei, R. A. Widenhoeffer, Chem. Commun. 2002, 650; (b) T. Pei, X. WANG, R. A. Widenhoefer, J. Am. Chem. Soc. 2003, 125, 648 .
23 D. YANG, J.-H. LI, Q. GAO, Y.-L. YAN, Org. Lett. 2003, 5, 2869.

24 (a) J. T. Link, Org. React. 2002, 60, 157; (b) R. H. НесK, Org. React. 1982, 27, 345.

25 (a) K. Karabelas, A. Hallberg, Tetrahedron Lett. 1985, 26, 3131;

(b) K. Karabelas, C. Westerlund, A. Hallberg, J. Org. Chem. 1985, 50, 3896; (c) K. Karabelas, A. Hallberg, J. Org. Chem. 1986, 51, 5286;

(d) K. Karabelas, A. Hallberg, J. Org. Chem. 1988, 53, 4909.

26 M. M. Abelman, T. Oh, L. E. Overman J. Org. Chem. 1987, 52, 4130.

27 (a) T. JEFFERY, Tetrahedron Lett. 1991, 32, 2121; (b) T. Jefferer, J. Chem. Soc., Chem. Commun. 1991, 324.

28 (a) Y. SATo, M. Sodeoka, M. SHibasaki, J. Org. Chem. 1989, 54, 4738; (b) Y. SATO, M. Sodeoka, M. Shibasaki, Chem. Lett. 1990, 1953; (c) M. SHibasaki,

C. D. J. Boden, A. Kojima, Tetrahedron 1997, 53, 7371; (d) A. B. Dounay, L. A. Overman, Chem. Rev. 2003, 103, 2945.

29 (a) R. GRigG, V. Loganathan, V. Santhakumar, V. SRidharan, A. Teasdale, Tetrahedron Lett. 1991, 32, 687; (b) W. Cabri, I. CANDIANI, A. Bedeschi, S. Penco, J. Org. Chem. 1992, 57, 1481; (c) W. Carbi, I. Candiani, Acc. Chem. Res. 1995, 28, 2.

30 D. Flubacher, G. Helmchen, Tetrahedron Lett. 1999, 40, 3867.

31 (a) R. C. Larock, J. M. Zenner, J. Org. Chem. 1995, 60, 482; (b) J. M. ZennNer, R. C. Larock, J. Org. Chem. 1999, 64, 7312.

32 G. Poli, G. Giambastiani, A. Mordini, J. Org. Chem. 1999, 64, 2962.

33 K. Fuji, N. Kinoshita, K. Tanaka, Chem. Commun. 1999, 1895.

34 (a) T. TABUChI, J. InANAGA, M. Yamaguchi, Tetrahedron Lett. 1986, 27, 1195; (b) T. TABuchi, J. InANAGA, M. YAMAGUCHI, Tetrahedron Lett. 1987, 28,215

35 Y. Masuyama, N. Kinugawa, Y. Kurusu, J. Org. Chem. 1987, 52, 3702.

36 (a) J. P. TAkAhara, Y. MASUYAMA, Y. Kurusu, J. Am. Chem. Soc. 1992, 114, 2577; (b) Y. Masuyama, R. Hayashi, K. Otake, Y. Kurusu, J. Chem. Soc., Chem. Commun. 1988, 44; 
50 1 Organic Synthesis with Bimetallic Systems

(c) Y. Masuyama, J. P. Takahara, Y. Kurusu, J. Am. Chem. Soc. 1988, 110, 4473.

37 (a) K. YASUi, Y. Goto, T. Yajima, Y. TANiseki, K. Fugami, A. TANAKA, Y. TAMARU, Tetrahedron Lett. 1993, 34, 7619; (b) Y. TAMaru, A. TANaKa, K. Yasui, S. Goto, S. Tanaka, Angew. Chem. Int. Ed. Engl. 1995, 34, 787.

38 (a) M. Kimura, I. KiYAMA, T. TOMiZaWA, Y. Horino, S. TANAKa, Y. TAMARU, Tetrahedron Lett. 1999, 40, 6795;

(b) Y. Tamaru, J. Organomet. Chem. 1999, 576, 215.

39 (a) S. Araki, T. Kamei, T. Hirashita, H. Yamamura, M. KawaI, Org. Lett. 2000, 2, 847; (b) S. Araki, K. Kameda, J. TANAKa, T. Hirashita, H. Yamamura, M. Kawai, J. Org. Chem. 2001, 66, 7919.

40 S.-K. Kang, S.-W. LeE, J. JunG, Y. Lim, J. Org. Chem. 2002, 67, 4376.

41 (a) W. Oppolzer, F. Schröder, Tetrahedron Lett. 1994, 35, 7939; (b) W. Oppolzer, J. Ruiz-Montes, Helv. Chim. Acta 1993, 76, 1266.

42 (a) H. Nakamura, N. Asao, Y. Yamamoto, J. Chem. Soc., Chem. Commun. 1995 , 1273; (b) H. NaKamura, H. Iwama, Y. Yамамото, Chem. Commun. 1996 , 1459; (c) H. NaKamura, H. Iwama, Y. Yамамото, J. Am. Chem. Soc. 1996, $118,6641$.

43 H. NAKAMURA, K. NAKamura, Y. Yамамото, J. Am. Chem. Soc. 1998, 120, 4242.

44 R. A. Fernandes, A. Stimac, Y. Yамамото, J. Am. Chem. Soc. 2003, 125, 14133

45 K. Nakamura, H. Nakamura, Y. Үамамото, J. Org. Chem. 1999, 64 2614.

46 (a) Y. SATo, M. TAKimoto, K. Hayashi, T. Katsuhara, K. TAKagi, M. Mori, J. Am. Chem. Soc. 1994, 116, 9771; (b) Y. SAто, M. ТАкімото, M. Mori, Tetrahedron Lett. 1996, 37, 887.

47 (a) M. Kitamura, A. Ezoe, K. Shibata, Y. Tamaru, J. Am. Chem. Soc. 1998, 120, 4033; (b) M. Kimura, A. Ezoe, S. Tanaka, Y. Tamaru, Angew. Chem. Int. Ed. 2001, 40, 3600.

48 (a) M. Kimura, H. Fujimatsu, A. Ezoe, K. Shibata, M. Shimizu, S. Matsumoto, Y. Tamaru, Angew. Chem. Int. Ed. 1999,
38, 397; (b) K. Shibata, M. Kimura, M. Shimizu, Y. TAMARU, Org. Lett. 2001, 3, 2181.

49 (a) J. Montgomery, A. V. Savchenko, J. Am. Chem. Soc. 1996, 118, 2099; (b) J. Montgomery, E. Oblinger, A. Savchenko, J. Am. Chem. Soc. 1997, 119, 4911.

50 E. Oblinger, J. Montgomery, J. Am. Chem. Soc. 1997, 119, 9065.

51 M. V. Chevliakov, J. Montgomery, Angew. Chem. Int. Ed. 1998, 37, 3144.

52 X.-Q. TAng, J. Montgomery, J. Am. Chem. Soc. 1999, 121, 6098.

53 (a) K. M. Miller, W.-S. Huang, T. F. Jamison, J. Am. Chem. Soc. 2003, 125, 3442; (b) E. A. Colby, T. F. Jamison, J. Org. Chem. 2003, 68, 156.

54 S. J. Patel, T. F. Jamison, Angew. Chem. Int. Ed. 2003, 42, 1364.

55 C. Molinaro, T. F. Jamison, J. Am. Chem. Soc. 2003, 125, 8076

56 K. Takai, K. Kimura, T. Kuroda, T. Hiyama, H. Nozaki, Tetrahedron Lett. 1983, 24, 5281.

57 (a) K. Takai, M. Tagashira, T. Kuroda, K. Oshima, K. Utimoto, H. Nozaki, J. Am. Chem. Soc. 1986, 108, 6048; (b) H. Jin, J. Uenishi, W. J. Christ, Y. Kishi, J. Am. Chem. Soc. 1986, 108, 5644; (c) Y. Kishi, Pure Appl. Chem. 1992, 64, 343.

58 (a) A. Fürstner, N. Shi, J. Am. Chem. Soc. 1996, 118, 12349; (b) A. FürSTNER, Chem. Rev. 1999, 99, 991.

59 (a) H.-w. Choi, K. NaKajima, D. Demeke, F.-A. KANG, H.-S. JUN, Z.-K. WAN, Y. KisHi, Org. Lett. 2002, 4, 4435; (b) Z.-K. WAN, H.-w. ChOI, F.-A. KANG, K. Nakajima, D. Demeke, Y. Kishi, Org. Lett. 2002, 4, 4431.

60 (a) V. Farina, V. Krishnamurthy, W. J. SCOTT, Org. React. 1997, 50, 3; (b) V. Farina, Pure Appl. Chem. 1996, 68, 73.

61 (a) L. S. Liebeskind, R. W. Fengl, J. Org. Chem. 1990, 55, 5359; (b) L. S. LiebesKIND, J. WAND, Tetrahedron Lett. 1990, 31, 4293; (c) L. S. Liebeskind, M. S. Yu, R. H. Yu, J. Wang, K. S. Hagen, J. Am. Chem. Soc. 1993, 115, 9048.

62 V. Farina, S. Kapadia, B. Krishnan, C. Wang, L. S. Liebeskind, J. Org. Chem. 1994, 59, 5905. 
63 W.-S. Kim, H.-J. Кim, C.-G. Сно, J. Am. Chem. Soc. 2003, 125, 14288

64 (a) J. Ye, R. K. BhatT, J. R. FALCK, J. Am. Chem. Soc. 1994, 116, 1; (b) J. R. FALCK, R. K. BhatT, J. Ye, J. Am. Chem. Soc. 1995, 117, 5973.

65 (a) Y. Nishimara, K. IKEgashira, A. Mori, T. Hiyama, Chem. Lett. 1997, 1233; (b) Y. NishiHARA, K. IKEgASHIRA, K. Hirabayashi, J. Ando, A. Mori, T. Hiyama, J. Org. Chem. 2000, 65, 1780; (c) Y. Nishihara, J. Ando, T. Kato, A. Mori, T. Hiyama, Macromolecules 2000, 33, 2779.

66 Y. Nishimara, M. Takemura, A. Mori, K. Osakada, J. Organomet. Chem. 2001, 620, 282.

67 (a) K. Sonogashira, Y. Tohda, N. Hagihara, Tetrahedron Lett. 1975, 50, 4467; (b) K. Sonogashira, T. YataKe, Y. Tohda, S. Takahashi, N. Hagihara, J. Chem. Soc., Chem. Commun. 1977, 291 (c) K. Sonogashira, Comprehensive Organic Synthesis, Vol. 3 (Eds.: B. M. Trost, I. Fleming), Pergamon, Oxford, 1991, p. 521; (d) K. Sonogashira, J. Organomet. Chem. 2002, 653, 46

68 (a) M. Alami, G. Linstrumelle, Tetrahedron Lett. 1991, 32, 6109; (b) M. Alami, F. Ferri, G. Linstrumelle, Tetrahedron Lett. 1993, 34, 6403.

69 P. Bertus, P. Pale, Tetrahedron Lett. 1996, 37, 2019.

70 (a) G. T. Crisp, P. D. Turner, K. A. Stephens, J. Organomet. Chem. 1998, 570, 219; (b) Y. Azuma, A. Sato, M. Morone, Heterocycles 1996, 42, 789; (c) L. Anastasia, E. Negishi, Org. Lett. 2001, 3, 3111

71 T. Kawasaki, Y. Үамамото, J. Org. Chem. 2002, 67, 5138

72 A. Arcadi, F. Marinelli, Synthesis 1986, 749.

73 T. SaKamoto, Y. Kondo, S. Iwashita, T. Nagano, H. YamanaKa, Chem. Pharm. Bull. 1988, 36, 1305.

74 N. G. Kundu, M. Pal, J. Chem. Soc. Chem. Commun. 1993, 86.

75 (a) X. Liu, X. Huang, S. Ma, Tetrahedron Lett. 1993, 34, 5963; (b) X. LU, G. CHEN, L. XIA, G. Guo, Tetrahedron: Asymmetry 1997, 8, 3067

76 T. Hosokawa, S. Aoki, M. Takano, T. NaKahira, Y. Yoshida, S. Murahashi,
J. Chem. Soc., Chem. Commun. 1991, 1559.

77 T. Hosokawa, M. Takano, Y. Kuroki, S. Murahashi, Teterahedron Lett. 1992, 33, 6643.

78 V. I. Timokhin, N. R. Anastasi, S. S. Stahl, J. Am. Chem. Soc. 2003, 125, 12996.

79 M. Sawamura, M. Sudoh, Y. Ito, J. Am. Chem. Soc. 1996, 118, 3309

80 J. Tsuji, I. Minami, I. Shimizu, Tetrahedron Lett. 1983, 24, 4713.

81 (a) J. Tsuji, I. Minami, I. Shimizu, Tetrahedron Lett. 1983, 24, 5639;

(b) I. Minami, K. Takahashi, I. Shimizu, T. Kimura, J. Tsuji, Tetrahedron 1986, 42, 2971.

82 T. SATOH, M. IKedA, M. Miura, M. Nomura, J. Org. Chem. 1997, 62, 4877.

83 S.-C. Yang, C.-W. Hung, J. Org. Chem. 1999, 64, 5000.

84 S. Камijo, T. Jin, Z. Huo, Y. Үамамото, J. Am. Chem. Soc. 2003, 125, 7786.

85 S. Kamijo, T. Jin, Z. Huo, Y. Үамамото, J. Org. Chem. 2004, 69, 2386.

86 S. Камijo, T. Jin, Y. Үамамото, Tetrahedron Lett. 2004, 45, 689.

87 (a) B. M. Trost, S. A. King, Tetrahedron Lett. 1986, 27, 5971; (b) B. M. Trost S. A. King, T. Schmidt, J. Am. Chem. Soc. 1989, 111, 5902; (c) B. M. Trost, S. A. King, J. Am. Chem. Soc. 1990, 112, 408.

88 (a) B. M. Trost, S. Sharma, T. Schmidt, J. Am. Chem. Soc. 1992, 114, 7903;

(b) B. M. Trost, S. Sharma, T. Schmidt, Tetrahedron Lett. 1993, 34, 7183.

89 (a) K. Hori, H. Kodama, T. OHta, I. Furukawa, Tetrahedron Lett. 1996, 37, 5947; (b) K. Hori, H. Kodama, T. ОhtA, I. Furukawa, J. Org. Chem. 1999, 64, 5017.

90 (a) P. A. Wender, H. TAKahashi, B. Witulski, J. Am. Chem. Soc. 1995 , 117, 4720; (b) P. A. WENDER, A. J. Dyckman, C. O. Husfeld, D. Kadereit, J. A. Love, H. Rieck, J. Am. Chem. Soc. 1999, 121, 10442.

91 (a) P. A. Wender, C. O. Husfeld, E. Langkopf, J. A. Love, J. Am. Chem. Soc. 1998, 120, 1940; (b) P. A. WENDER, C. O. Husfeld, E. Langkopf, J. A. Love, N. Pleuss, Tetrahedron 1998, 54, 7203. 
52 1 Organic Synthesis with Bimetallic Systems

92 P. A. Wender, F. Glorius, C. G. HusFeld, E. Langkopf, J. A. Love, J. Am. Chem. Soc. 1999, 121, 5348.

93 B. M. Trost, H. C. Shen, Org. Lett. 2000 , 2, 2523

94 P. A. Wender, A. G. Correa, Y. Sato, R. Sun, J. Am. Chem. Soc. 2000, 122, 7815.

95 B. Wang, P. CaO, X. Zhang, Tetrahedron Lett. 2000, 41, 8041.

96 S. R. Gilbertson, B. DeBoef, J. Am. Chem. Soc. 2002, 124, 8784.

97 A. P. Evans, J. E. Robinson, E. W. Baum, A. N. Fazal, J. Am. Chem. Soc. 2002, 124, 8782.

98 (a) S. Ikeda, N. Mori, Y. SAto, J. Am. Chem. Soc. 1997, 119, 4779; (b) S. IKEDA, H. Watanabe, Y. Sato, J. Org. Chem. 1998, 63, 7026.

99 J. E. Lyons, H. K. Myers, A. Schneider, J. Chem. Soc., Chem. Commun. 1978, 636.

100 (a) M. Lautens, C. M. CRudden, Organometallics 1989, 8, 2733;

(b) M. Lautens, W. Tam, L. G. Edwards, J. Org. Chem. 1992, 57, 8.

101 M. Lautens, J. C. Lautens, A. C. Smith, J. Am. Chem. Soc. 1990, 112, 5627.

102 (a) I.-F. Duan, C.-H. Cheng, J.-S. Shaw, S.-S. Cheng, K. F. Liou, J. Chem. Soc., Chem. Commun. 1991, 1346;

(b) O. Pardigon, A. Tenaglia, G. Buono, J. Org. Chem. 1995, 60, 1868.

103 (a) M. Lautens, W. Tam., J. C. Lautens, L. G. Edwards, C. M. Crudden, A. C. Sмith, J. Am. Chem. Soc. 1995, 117, 6863; (b) Y. Chen, R. Kiattansakul, B. Ma, J. K. Snyder, J. Org. Chem. 2001, 66, 6932.

104 N. Jeong, S. D. Seo, J. Y. Shin, J. Am. Chem. Soc. 2000, 122, 10220.

105 P. CaO, B. Wang, X. Zhang, J. Am. Chem. Soc. 2000, 122, 6490.

106 P. Cao, X. Zhang, Angew. Chem. Int. Ed. 2000, 39, 4104.

107 B. M. Trost, J. M. Tour, J. Am. Chem. Soc. 1987, 109, 5268.
108 (a) S. Kamijo, Y. Yamamoto, Angew. Chem. Int. Ed. 2002, 41, 3230;

(b) S. Камijo, Y. Үамамото, J. Org. Chem. 2003, 68, 4764.

109 M. Akazome, T. Kondo, Y. Watanabe, J. Org. Chem. 1994, 59, 3375.

110 Y. Nishibayashi, M. Yoshikawa, Y. InAda, M. D. Milton, M. Hidai, S. Uemura, Angew. Chem. Int. Ed. 2003, 42, 2681.

111 M. Sodeoka, K. Ohrai, M. Shibasaki, J. Org. Chem. 1995, 60, 2648.

112 C. WeI, C.-J. LI, Green Chem. 2002, 4, 39.

113 C.-J. LI, C. WeI, Chem. Commun. 2002, 268.

114 B. M. Trost, M. Portnoy, H. Kurihara, J. Am. Chem. Soc. 1997, 119, 836.

115 B. M. Trost, A. B. Pinkerton, J. Am. Chem. Soc. 1999, 121, 1988.

116 B. M. Trost, A. B. Pinkerton, Angew. Chem. Int. Ed. 2000, 39, 360.

117 M. Shi, Y. Chen, B. Xu, Org. Lett. 2003, 5, 1225.

118 T. Tsuchimoto, S. Kamiyama, R. Negoro, E. Shirakawa, Y. KawaKami, Chem. Commun. 2003, 852.

119 B. M. Trost, R. C. Livingston, J. Am. Chem. Soc. 1995, 117, 9586.

120 N. Tsukada, T. Mitsuboshi, H. Setoguchi, Y. Inoue, J. Am. Chem. Soc. 2003, 125, 12102.

121 N. Asao, S. Kit, H. Hanawa, K. Maruoka, Tetrahedron Lett. 1998, 39, 3729.

122 S. KiI, K. MARUoKa, Tetrahedron Lett. 2001, 42, 1935.

123 S. Kit, T. Hashimoti, K. Maruoka, Synlett 2002, 931.

124 H. Siebeneicher, I. Bytschkov, S. Doye, Angew. Chem. Int. Ed. 2003, 42, 3042.

125 B. M. Trost, M. R. Machacek, Angew. Chem. Int. Ed. 2002, 41, 4693.

126 T. Shimada, K. Mukaide, A. Shinohara, J. W. Han, T. Hayashi, J. Am. Chem. Soc. 2002, 124, 1584.

127 R. Grigg, E. L. Millington, M. Thornton-Pett, Tetrahedron Lett. 2002, 43, 2605. 